\title{
EXPERIMENTAL STUDY ON THE MECHANICAL BEHAVIOUR OF Q345 STEEL HIGH-STRENGTH BOLT BEARING-TYPE CONNECTIONS
}

\author{
Jing-Yao Li ${ }^{1,2}$, Shi-Dong Nie ${ }^{1,2, *}$, Jia Zeng ${ }^{2,3}$ and Bo Yang ${ }^{1,2}$ \\ ${ }^{1}$ Key Laboratory of New Technology for Construction of Cities in Mountain Area (Chongqing University), Ministry of Education, Chongqing, China. \\ ${ }^{2}$ School of Civil Engineering, Chongqing University, Chongqing, China. \\ ${ }^{3}$ China Southwest Architectural Design and Research Institute Corp., Ltd., Chengdu, China. \\ *(Corresponding author: E-mail: nieshidong@cqu.edu.cn)
}

\section{A B S T R A C T}

Static tensile tests were performed on 45 sets of Q345 steel high-strength bolt bearing-type connections, in which grade 10.9 and 12.9 high-strength bolts were used. In the tests, tearout failure, splitting failure, pure bearing failure, net cross section failure and bolt shear failure were observed. The effect of the thickness and geometrical dimensions of the test plates, and the property grade, diameter, pretension, layout of the bolts on the load-carrying capacity and deformation of the connections were investigated. Further, the experimental results were compared with the calculated values that employed the design methods in GB 50017-2017, Eurocode 3, and the AISC 360-10. And finally, the applicability of the calculation methods in various specifications to the connections with two bolts arranged parallelly to the load was discussed. It was found that bolt specifications controlled the occurrence of the shear failure mode, and the pretension of bolts improved the load-carrying capacity and peak displacement of the specimens with bolt shear failure. Meanwhile, the calculation methods in GB50017-2017 and Eurocode 3 were conservative for predicting the load-carrying capacity of connections, and the calculated resistance using method 2 in AISC360-10 was the closest to the experimental results. And for the shear connection with two bolts arranged parallelly to the load and with a relatively small end distance, the resistance calculated by the simple summation method in Eurocode 3 or AISC360-10 would be higher than the actual load-carrying capacity.

\section{A R T I C L E H I S T O R Y}

$\begin{array}{ll}\text { Received: } & \text { 19 April 2020 } \\ \text { Revised: } & \text { 29 December } 2020 \\ \text { Accepted: } & \text { 29 December 2020 }\end{array}$

\section{KEYWOR D S}

Q345;

Bolted connection;

Shear connection;

High-strength bolts

Experimental study

\section{Introduction}

With the development of architectural concepts and construction technology, steel structures play an important role in modern engineering constructions. And bolted connections are prevalent in steel constructions and the relevant studies started early ${ }^{[1-4]}$. Recently, the studies on the shear connection with high-strength bolts were primarily focused on the bearing performance test of single-bolt ${ }^{[5-9]}$, two bolts ${ }^{[8,10]}$ and multiple bolts ${ }^{[11,12]}$ shear connections. Moreover, the effect of the geometrical dimensions of the plate, the layout properties of the bolt holes ${ }^{[13,14]}$ and the material properties ${ }^{[15]}$ on the resistance and deformation of the specimen were discussed. In the past decades, high strength bolts with nominal tensile strengths of over $800 \mathrm{MPa}$ were widely used in building engineering and the behaviour was investigated ${ }^{[16]}$. Pretension was required for the high-strength bolts in most cases, while it was not taken into consideration in most investigations.

On the other hand, the discussion on the accuracy of the calculation methods in codes or specifications is also an important topic, which was involved in many previous papers about the performance of high-strength steel members ${ }^{[17-19]}$. And for the Chinese Code for Steel Structure Design, some previous studies ${ }^{[20-23]}$ showed that the calculation methods of load-carrying capacity and bolt shear capacity in the GBJ $17-88^{[24]}$ (an earlier vision of the Chinese Code for Steel Structure Design published in 1988) were conservative. And From the GBJ 17-88 to the current standard for steel structure design (GB50017-2017) ${ }^{[25]}$, the calculation methods of the bearing capacity, the net section carrying capacity, and the bolt shear capacity of the bearing-type connection remain they were. Meanwhile, the relationship between the design value of bearing strength of steel and their ultimate strength, and the relationship between the design value of shear strength of high-strength bolts and their ultimate strength have not changed. Accordingly, the relevant study results of the GBJ 17-88 can be used to indicate the current one. While there were few discussions on the accuracy of calculation methods in the European code ${ }^{[26]}$ and the US specification ${ }^{[27]}$. Therefore, it is necessary to conduct the study through experiments.

In the current study of this paper, static tensile tests were conducted on 45 sets of Q345 steel high-strength bolted bearing-type connections. Based on the test results, the influence of bolt pretension on the load-carrying capacity and deformation of the connection was primarily studied. Further, the strength and the diameters of bolts, geometric dimensions of the test plates, such as end distances and edge distances, were discussed. And finally, the experimental results were compared with the calculated values that using the methods in the Chinese Standard for Steel Structure Design, European code, and the US specification

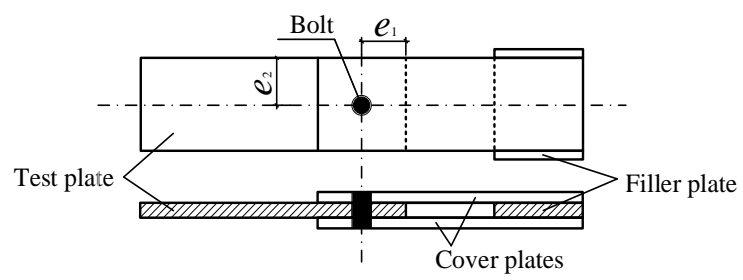

(a) A-series specimens: connection with a single bolt

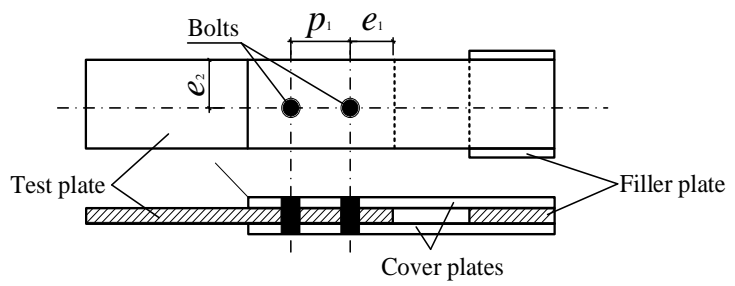

(b) B-series specimens: connection with two bolts arranged parallelly to the load

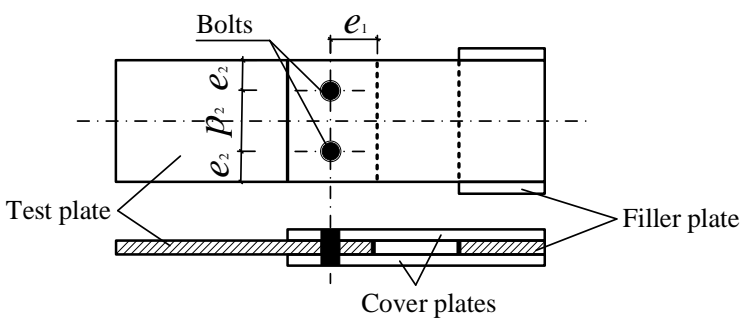

(c) C-series specimens: connection with two bolts arranged perpendicularly to the load

Fig. 1 Three series of specimens 

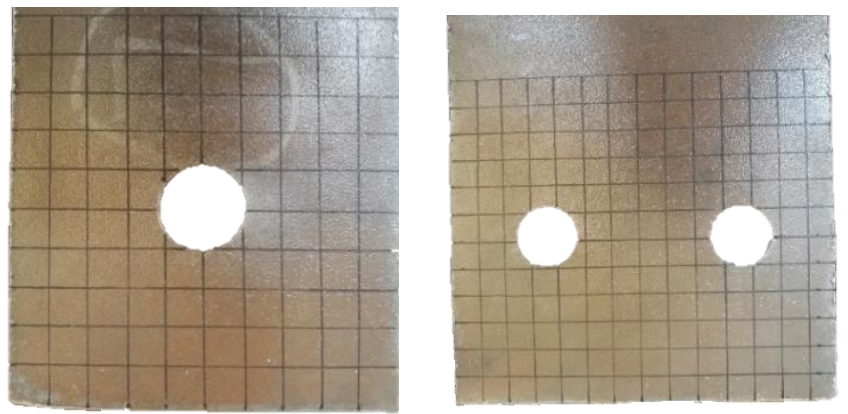

Fig. 2 The grid drawn on the test plate contact surface
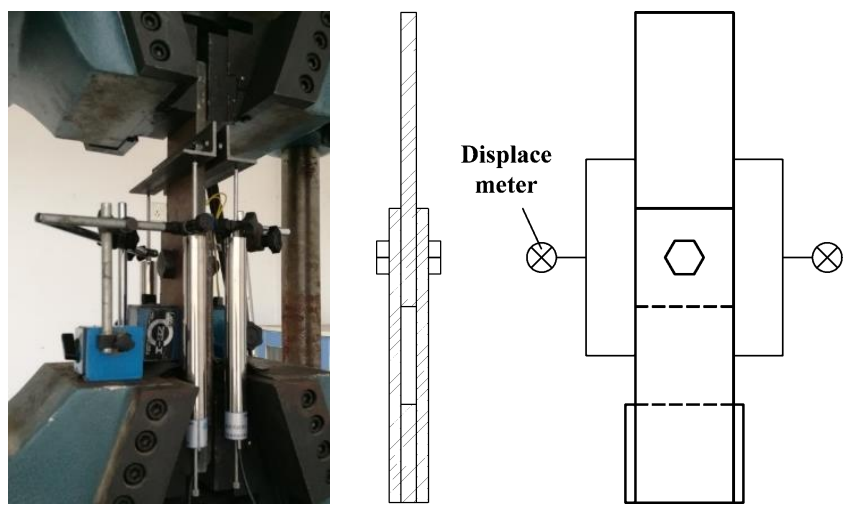

Fig. 3 Loading device and measuring point layout

\section{Test overview}

\subsection{Specimens design and processing}

The experimental test objects were the bearing-type shear connections of Q345 steel combined high-strength bolts with grade 10.9 or 12.9. Each specimen consists of a test plate, cover plates, high-strength bolts, and a filler plate. When designing the test plate, the effect of the thickness and geometrical dimensions of the test plates, and the property grade, diameter, pretension, layout of the bolts were considered and be set as variables, in which the layout includes the end distance, edge distance and pitch. According to the above concern, the designed specimens can be divided into three kinds according to the number of bolts and their layout: single bolt, two bolts arranged parallelly to the load, and two bolts arranged perpendicularly to the load. And the three kinds of specimens can be named as the "A", "B" and "C" series, where "A" represents the layout of a single bolt, "B" and "C" represent two bolts arranged parallelly or perpendicularly to the load, which are shown in Fig. 1.

45 groups of double-shear high-strength bolt bearing-type connections were designed, including 29 groups of Q345+12.9M20 specimens, 8 groups of Q345+10.9M20 specimens, and 8 groups of Q345+10.9M16 specimens. While if classifying according to the bolt layout, there were 19 groups of A-series specimens, 6 groups of B-series specimens and 20 groups of $\mathrm{C}$-series specimens All the plates of the specimens in this study were manufactured with the same grade of steel, that is Q345 specifically. The geometrical dimensions (end distance, edge distance, and pitch) of the test plates and cover plates remain the same. And the nominal diameter of the high-strength bolts used in this current study was $16 \mathrm{~mm}$ or $20 \mathrm{~mm}$.

The specimens processing in this test includes the following steps: steel plate surface treatment, blanking, drilling, descaling, assembling and splint welding, etc. The surface treatment process of the steel plate was done before the blanking and drilling of the steel plate due to the small size of the steel plates, which caused less workload than the treatment process done after the blanking and drilling. After drilling, the steel plates were exposed to indoor air for 30 days. Before assembling, the rust was removed with a wire brush; subsequently, the actual size of the plate was measured.

The actual dimensions of the specimens are measured and listed in Table 1. The naming of the specimens contains the information of bolts layout type, strength grade of bolts and serial number, and there is a sign $n$ to show if the bolts pretension is applied: the appearance of the $n$ represents the specimen without bolt pretension. The width of the test plates is the width of the crosssection at the bolt hole, and the thickness of the test plates is the average of the thickness at the bolt holes and the thickness at the edge of the weakened crosssection. When the bolt hole diameter $d_{0}$, the end distance $e_{1}$, the edge distance $e_{2}$, the pitch $p_{1}$ and the lateral pitch $p_{2}$ have multiple values, the average value is taken. To facilitate the local deformation observation of the test plates after the test piece failed, grids with a geometry of $1 \mathrm{~cm} \times 1 \mathrm{~cm}$ was drawn on the contact surface of the test plate and cover plate, as shown in Fig. 2.

\subsection{Loading device and loading system}

The loading device of the shear-connection tensile tests is shown in Fig. 3 . Two displacement meters (DM) with a measuring range of $50 \mathrm{~mm}$ were equipped on both sides of the specimen, and another displacement meter was equipped at the position between the fixture and the measuring point at the top of the specimen to monitor the slipping between the fixture and the plate.

During the test, it was preloaded to $5 \mathrm{kN}$ and subsequently unloaded to ensure that the loading device function well and reliable. Thereafter, the tensile test was subsequently started. Monotonic loading was performed at a loading rate of $1.0 \mathrm{kN} / \mathrm{s}$ until the load-carrying capacity of the specimen reduced to $85 \%$ of its peak, at which the loading was then stopped. During this period, the force exerted by the tension tester was recorded by the force sensor of the machine, and the displacement meter was recorded by the DH3816N acquisition instrument.

Table 1

Actual dimensions of the test plates

\begin{tabular}{|c|c|c|c|c|c|c|c|}
\hline Specimen & $\begin{array}{l}\text { Width of test plates } \\
\qquad b(\mathrm{~mm})\end{array}$ & $\begin{array}{l}\text { Thickness of test plates } \\
\qquad t(\mathrm{~mm})\end{array}$ & $\begin{array}{l}\text { Bolt hole diameter } \\
\qquad d_{0}(\mathrm{~mm})\end{array}$ & $\begin{array}{l}\text { End distance } \\
\qquad e_{1}(\mathrm{~mm})\end{array}$ & $\begin{array}{l}\text { Edge distance } \\
\qquad e_{2}(\mathrm{~mm})\end{array}$ & $\begin{array}{c}\text { Pitch } \\
p_{1}(\mathrm{~mm})\end{array}$ & $\begin{array}{l}\text { Lateral pitch } \\
p_{2}(\mathrm{~mm})\end{array}$ \\
\hline A-12.9-1 & 99.97 & 14.53 & 22.48 & 47.61 & 50.08 & - & - \\
\hline A-12.9-1n & 99.26 & 13.90 & 22.35 & 50.66 & 49.58 & - & - \\
\hline A-12.9-2 & 101.20 & 13.86 & 22.38 & 51.68 & 50.72 & - & - \\
\hline A-12.9-3 & 100.82 & 9.76 & 22.58 & 50.24 & 50.69 & - & - \\
\hline A-12.9-4 & 100.28 & 16.01 & 22.63 & 49.37 & 51.02 & - & - \\
\hline A-12.9-5 & 79.42 & 13.88 & 22.65 & 48.76 & 39.93 & - & - \\
\hline A-12.9-5n & 80.26 & 13.68 & 22.74 & 47.25 & 40.25 & - & - \\
\hline A-12.9-6 & 122.64 & 13.75 & 21.98 & 49.04 & 61.12 & - & - \\
\hline A-12.9-6n & 122.15 & 13.64 & 22.17 & 48.87 & 60.78 & - & - \\
\hline A-12.9-7 & 100.49 & 13.97 & 22.53 & 30.49 & 50.11 & - & - \\
\hline A-12.9-7n & 101.55 & 13.92 & 22.53 & 31.17 & 50.63 & - & - \\
\hline A-12.9-8 & 102.83 & 14.32 & 22.30 & 40.65 & 51.34 & - & - \\
\hline A-12.9-8n & 102.73 & 14.29 & 22.36 & 40.10 & 51.54 & - & - \\
\hline A-12.9-9 & 103.56 & 13.80 & 22.26 & 59.48 & 51.34 & - & - \\
\hline
\end{tabular}




\begin{tabular}{|c|c|c|c|c|c|c|c|}
\hline Specimen & $\begin{array}{l}\text { Width of test plates } \\
\qquad b(\mathrm{~mm})\end{array}$ & $\begin{array}{c}\text { Thickness of test plates } \\
t \quad(\mathrm{~mm})\end{array}$ & $\begin{array}{l}\text { Bolt hole diameter } \\
\qquad d_{0}(\mathrm{~mm})\end{array}$ & $\begin{array}{l}\text { End distance } \\
\qquad e_{1}(\mathrm{~mm})\end{array}$ & $\begin{array}{l}\text { Edge distance } \\
\qquad e_{2}(\mathrm{~mm})\end{array}$ & $\begin{array}{c}\text { Pitch } \\
p_{1}(\mathrm{~mm})\end{array}$ & $\begin{array}{l}\text { Lateral pitch } \\
\qquad p_{2}(\mathrm{~mm})\end{array}$ \\
\hline A-12.9-9n & 100.28 & 13.81 & 22.45 & 59.30 & 50.20 & - & - \\
\hline B-12.9-3 & 121.39 & 13.68 & 22.39 & 51.35 & 60.87 & 70.18 & - \\
\hline B-12.9-3n & 121.03 & 13.94 & 22.49 & 50.98 & 60.58 & 69.78 & - \\
\hline C-12.9-1 & 102.60 & 13.96 & 22.46 & 50.78 & 26.46 & - & 49.75 \\
\hline C-12.9-1n & 101.70 & 13.90 & 22.05 & 50.15 & 25.86 & - & 49.68 \\
\hline C-12.9-2 & 120.65 & 13.68 & 22.24 & 51.39 & 30.51 & - & 60.01 \\
\hline C-12.9-2n & 121.26 & 13.74 & 22.22 & 51.36 & 30.66 & - & 59.96 \\
\hline C-12.9-3 & 142.48 & 13.74 & 22.54 & 50.08 & 36.36 & - & 70.26 \\
\hline C-12.9-3n & 141.87 & 13.68 & 22.35 & 49.00 & 35.79 & - & 70.04 \\
\hline C-12.9-4 & 142.78 & 13.94 & 22.48 & 29.97 & 36.55 & - & 70.09 \\
\hline C-12.9-4n & 142.85 & 13.70 & 22.55 & 30.88 & 36.42 & - & 70.08 \\
\hline C-12.9-5 & 142.13 & 13.86 & 22.42 & 39.12 & 36.33 & - & 69.79 \\
\hline C-12.9-5n & 142.71 & 13.86 & 22.52 & 39.26 & 36.63 & - & 69.99 \\
\hline C-12.9-6 & 142.65 & 13.70 & 22.36 & 60.43 & 36.28 & - & 70.03 \\
\hline C-12.9-6n & 143.09 & 13.61 & 22.42 & 61.04 & 36.73 & - & 69.97 \\
\hline A-10.9-1 & 101.01 & 13.80 & 18.06 & 38.85 & 50.64 & - & - \\
\hline A-10.9-1n & 100.68 & 14.03 & 18.05 & 38.58 & 50.32 & - & - \\
\hline A-10.9-2 & 101.20 & 13.81 & 22.31 & 48.64 & 50.68 & - & - \\
\hline A-10.9-2n & 100.27 & 13.63 & 22.30 & 45.37 & 50.18 & - & - \\
\hline B-10.9-1 & 121.39 & 13.81 & 18.09 & 40.97 & 60.57 & 60.02 & - \\
\hline B-10.9-1n & 121.21 & 13.95 & 18.25 & 41.23 & 60.68 & 59.91 & - \\
\hline B-10.9-2 & 121.81 & 14.33 & 22.50 & 51.60 & 61.13 & 69.95 & - \\
\hline B-10.9-2n & 121.43 & 13.76 & 22.45 & 51.98 & 60.64 & 70.03 & - \\
\hline C-10.9-1 & 120.82 & 13.67 & 18.39 & 40.64 & 30.40 & - & 59.98 \\
\hline C-10.9-1n & 121.04 & 13.77 & 18.25 & 40.92 & 30.60 & - & 59.90 \\
\hline C-10.9-2 & 142.41 & 13.88 & 18.18 & 38.38 & 36.41 & - & 69.76 \\
\hline C-10.9-2n & 144.73 & 14.38 & 18.09 & 38.49 & 37.57 & - & 69.63 \\
\hline C-10.9-3 & 121.54 & 13.85 & 22.27 & 51.10 & 30.88 & - & 60.07 \\
\hline C-10.9-3n & 120.17 & 13.67 & 22.28 & 51.33 & 30.25 & - & 60.02 \\
\hline C-10.9-4 & 142.04 & 13.64 & 22.54 & 48.99 & 36.01 & - & 70.19 \\
\hline C-10.9-4n & 142.51 & 13.83 & 22.53 & 49.32 & 36.30 & - & 70.20 \\
\hline
\end{tabular}

\subsection{Material properties and torque coefficients of high-strength bolts}

The material properties of steel and the high-strength bolts used in the tests are listed in Table 2 and Table 3 respectively.

The tests of the torque coefficients of the high-strength bolt were performed to apply the pretension accurately to the specimens. These tests were following the requirement in "Specifications of high strength bolts with large hexagon head, large hexagon nuts, plain washers for steel structures (GB/T 1231-2006) [28]". Seven sets, and there were eight high-strength bolts in each set, of the torque coefficient measurement test were carried out. The average value and standard deviation of the torque coefficients of the high-strength bolt are shown in Table 4. The average torque coefficient of each batch is between 0.110 and 0.150 , and its standard deviation of the torque coefficient is less than 0.01 , which meets the requirements in GB/T 1231-2006 ${ }^{[28]}$.

In this test, a torque wrench was employed to apply pretension to bolts. According to the "Technical specifications for high-strength bolt connection of steel structures (JGJ 82-2011) [29]", the tightening of high-strength bolts is divided into two steps, which were initial tightening and final tightening respectively. The final construction tightening torque $T_{\mathrm{c}}$ shall be calculated by Eq. (1).

$T_{\mathrm{c}}=k P_{\mathrm{c}} d$

where, $T_{\mathrm{c}}$ is the final construction tightening torque, $k$ is the torque coefficient of the high-strength bolts, $P_{c}$ is the construction pretension value of high strength bolts, and $d$ is the nominal diameter of high strength bolts.
The initial tightening torque shall be half of the final construction tightening torque, i.e. $0.5 T_{\mathrm{c}}$. And the screwing sequence shall be performed from the middle bolts to both ends. The measured torque coefficients of the high-strength bolts and the final tightening torque, as well as the construction pretension in the test are listed in Table 5. The pretension value of the grade 10.9 high-strength bolt is specified in the "Technical specifications for high strength bolt

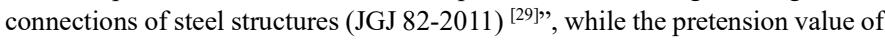
the grade 12.9 high-strength bolt is beyond the specification. According to the corresponding calculation rules, the construction pretension of the grade 12.9 high-strength bolt was determined, which is $205 \mathrm{kN}$. Considering the accuracy of the torque wrench, the construction torque is represented as an integral multiple of 25 , and the corresponding pretension value of the construction is obtained in the actual construction.

Table 2

Material properties of Q345 steel plates

\begin{tabular}{cccccc}
\hline Thickness of & Yield & Tensile & Peak & Yield & Elongation \\
steel plates & strength & strength & strain & ratio & $\%$ \\
$t(\mathrm{~mm})$ & $f_{\mathrm{y}}(\mathrm{MPa})$ & $f_{\mathrm{u}}(\mathrm{MPa})$ & $\%$ & & \\
\hline 10 & 356.87 & 494.81 & 16.86 & 0.72 & 36.31 \\
14 & 431.19 & 526.73 & 12.87 & 0.82 & 26.35 \\
16 & 430.77 & 586.54 & 13.74 & 0.73 & 30.73 \\
\hline
\end{tabular}


Table 3

Material properties of High-strength bolts

\begin{tabular}{|c|c|c|c|c|c|}
\hline \multirow{3}{*}{ Bolt specification } & Yield strength & Tensile strength & Peak strain & \multirow{3}{*}{ Yield ratio } & \multirow{3}{*}{$\begin{array}{c}\text { Elongation } \\
\%\end{array}$} \\
\hline & & & & & \\
\hline & $f_{\mathrm{y}}^{\mathrm{b}}(\mathrm{MPa})$ & $f_{\mathrm{u}}^{\mathrm{b}}(\mathrm{MPa})$ & $\%$ & & \\
\hline $10.9 \mathrm{M} 16 \times 70$ & 1066.9 & 1136.2 & 3.80 & 0.939 & 15.7 \\
\hline $10.9 \mathrm{M} 16 \times 75$ & 1054.5 & 1113.4 & 4.07 & 0.947 & 15.3 \\
\hline $10.9 \mathrm{M} 20 \times 70$ & 1152.6 & 1188.3 & 4.08 & 0.970 & 13.0 \\
\hline $10.9 \mathrm{M} 20 \times 80$ & 1152.2 & 1183.2 & 3.42 & 0.974 & 14.0 \\
\hline $10.9 \mathrm{M} 20 \times 85$ & 1198.3 & 1289.3 & 4.44 & 0.929 & 13.2 \\
\hline $12.9 \mathrm{M} 20 \times 70$ & 1347.6 & 1450.2 & 4.51 & 0.929 & 12.0 \\
\hline $12.9 \mathrm{M} 20 \times 75$ & 1355.3 & 1455.9 & 4.86 & 0.931 & 12.6 \\
\hline
\end{tabular}

Table 4

Pretension of high-strength bolt in the torque coefficient test

\begin{tabular}{ccccc}
\hline Bolt specification & & $10.9 \mathrm{M} 16$ & $10.9 \mathrm{M} 20$ & $12.9 \mathrm{M} 20$ \\
\hline Pretension $P(\mathrm{kN})$ & Max & 121 & 187 \\
\cline { 2 - 4 } & Min & 99 & 153 \\
\hline
\end{tabular}

Table 5

Measured torque coefficient and construction pretension of high-strength bolts

\begin{tabular}{|c|c|c|c|c|c|}
\hline Bolt & Torque coefficient & $\begin{array}{r}\text { Standard } \\
\text { deviation }\end{array}$ & $\begin{array}{l}\text { Pretension } \\
\qquad(\mathrm{kN})\end{array}$ & $\begin{array}{l}\text { Construction pretension } \\
\qquad(\mathrm{kN})\end{array}$ & $\begin{array}{c}\text { Construction tightening torque } \\
\qquad \mathrm{N} \cdot \mathrm{m}\end{array}$ \\
\hline 12.9-M20×70 & 0.1325 & 0.0032 & 185 & 208 & 550 \\
\hline 12.9-M20×75 & 0.1292 & 0.0026 & 185 & 203 & 525 \\
\hline $10.9-\mathrm{M} 20 \times 70$ & 0.1415 & 0.0047 & 155 & 168 & 475 \\
\hline 10.9-M20×80 & 0.1283 & 0.0076 & 155 & 175 & 450 \\
\hline $10.9-\mathrm{M} 20 \times 85$ & 0.1300 & 0.0030 & 155 & 173 & 450 \\
\hline 10.9-M16×70 & 0.1487 & 0.0093 & 100 & 116 & 275 \\
\hline 10.9-M16×75 & 0.1418 & 0.0085 & 100 & 110 & 250 \\
\hline
\end{tabular}

\section{Test Results}

\subsection{Failure mode}

Five failure modes were observed in the test: tearout failure, splitting failure, pure bearing failure, net cross-section failure, and bolt shear failure.

The tearout failure of a specimen was shown as Fig. 4, which occurred when the end distance was small while the edge distance was relatively large (net cross-section failure would not occur). The bolt extruded the steel plate forward, and the bolt hole was been lengthened until the damage occurred. When failed, there were clear shear lines and the "tearout block" at front of the bolt hole. When the end distance increased, the edge distance remains unchanged or increased with a rate that slower than the end distance, the failure mode of the specimen transformed to the splitting failure, as shown in Fig. 5. The front edge of the bolt hole was split, and the crack developed obliquely to the side of the elongated bolt hole. When the bolt hole was under pressure, the edge of the plate was in the high tensile stress area, which is shown in Fig. 6. The edges of the plate were tensioned causing the splitting in the edge of the plate. After the splitting occurred, the crack entered the high shear stress zone in a curved shape and ends at the high shear stress zone on the side of the elongated bolt hole, thus forming the splitting failure mode. In this test, only one specimen, A-10.9-2n, experienced pure bearing failure, as shown in Fig. 7. The specimen only appeared as a phenomenon of the elongation of the bolt hole. No obvious shear line appeared for this specimen, while a split appeared at the end of the test plate, which may be the bud of splitting failure, and if the load continued to be applied, it was very likely that splitting failure would occur. Another test piece, A-10.9-2, with the same dimensions as A-10.9-2n but a pretension of the bolt, was subjected to splitting failure, as shown in Fig. 8. Kim ${ }^{[15]}$, Rex ${ }^{[7]}$, Wang ${ }^{[6]}$, and Može ${ }^{[12]}$ have also observed splitting failure in their studies, and that pure bearing failure rarely occurred. Wang and Može have not observed pure bearing failure in their experimental studies. Accordingly, considering the small number of pure bearing failures in the experiment, and the impact on the ultimate load-carrying capacity of the connection is not obvious (A-10.9-2n is $5 \%$ higher than the ultimate load-carrying capacity of A-10.9-2), pure bearing failure is fallen into to splitting failure in the following discussion. Net cross-section failure occurs when the end distance of the test plate is large enough while the edge distance or pitch $p_{2}$ is relatively small. The net section of the weakened area is necked and even fractured, as shown in Fig. 9. Moreover, the failure was accompanied by obvious elongation of bolt holes in some tests. Bolt shear failure occurs when the bolts are weaker relatively than the plate. The bolts were damaged along the shear face of the bolt shank. The failure surface is smooth, as shown in Fig. 10. The bolt shear failure occurred in specimen B10.9-1, the bolt hole of the test plate was significantly deformed and even the edge of the plate was split.

In this study, mixed failure modes occurred, but the statistical failure mode was incorporated in the final failure mode. For example, the final failure mode of the specimen shown as Fig. 10 was regarded as bolt shear failure due to that the shearing happened first, although the edge of the plate in the force direction has been split. Table 6 lists the number of failure modes for different test specimen groups, where "TF", "SPF", "BF", "NF" and "SF" represent tearout failure, splitting failure, pure bearing failure, net cross-section failure and bolt shear failure respectively.

\section{Table 6}

Failure modes statistics

\begin{tabular}{ccc|ccccc|c}
\hline \multicolumn{3}{c|}{ Specimen information } & \multirow{2}{*}{ TF } & SPF & BF & NF & SF & Total \\
\hline \multirow{2}{*}{ Steel } & Bolt & Bolt & & & & & & \\
\hline \multirow{3}{*}{ Q345 } & 12.9 & M20 & 3 & 20 & 0 & 6 & 0 & 29 \\
\cline { 2 - 6 } & \multirow{2}{*}{10.9} & M20 & 0 & 5 & 1 & 2 & 0 & 8 \\
& & M16 & 0 & 0 & 0 & 0 & 8 & 8 \\
\hline
\end{tabular}




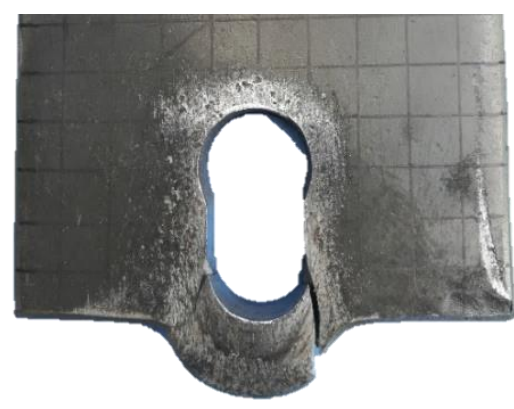

Fig. 4 Tearout failure
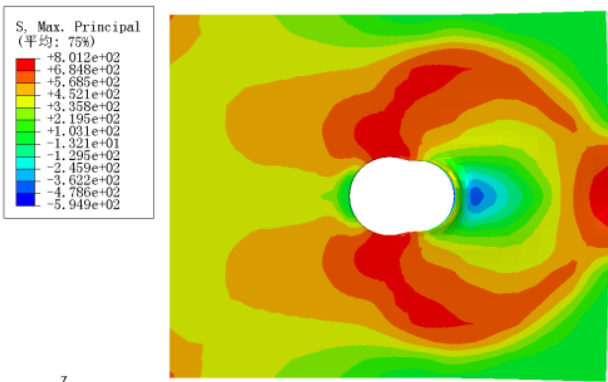

(a) Principal stress

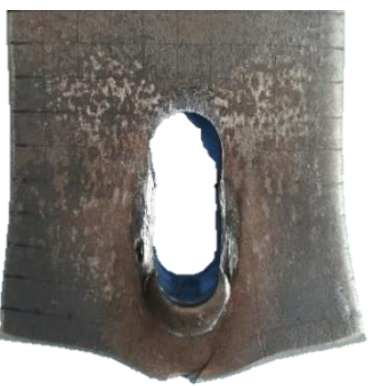

Fig. 5 Splitting failure

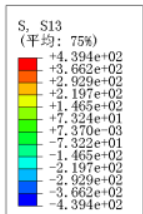

Fig. 6 The stress of test plate of the connection with a single bolt in tension

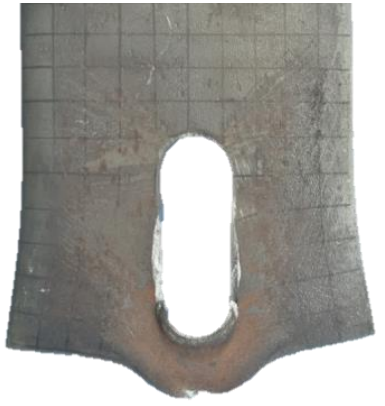

Fig. 7 Pure bearing failure

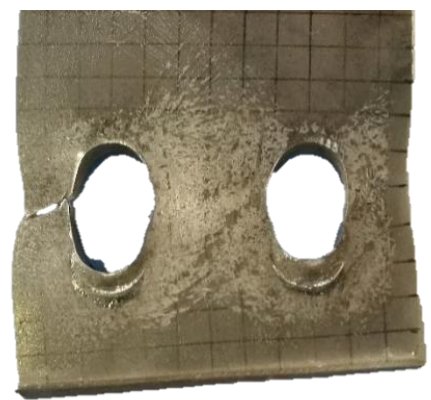

Fig. 9 Net cross-section failure

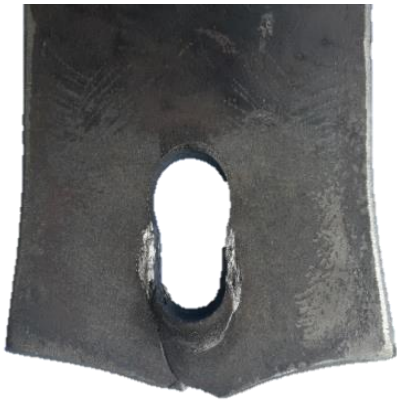

Fig. 8 A-10.9-2
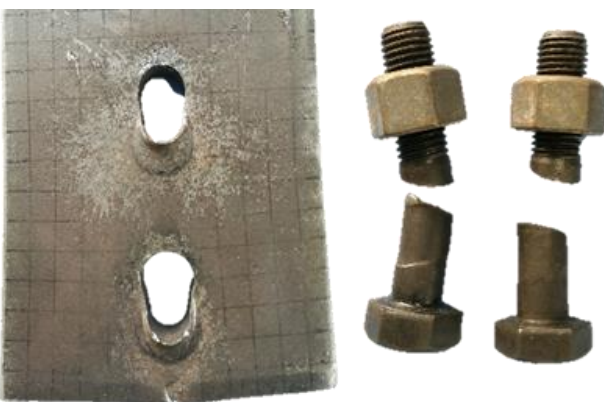

Fig. 10 Bolt shear failure

\subsection{Ultimate load-carrying capacity and deformation}

The ultimate load-carrying capacity and deformation of each specimen are shown in Table 7. In the table, $P_{\mathrm{c}}, F_{\mathrm{s}}, \Delta_{\mathrm{s}}, F_{\mathrm{u}}, \Delta_{\mathrm{p}}$ and $\Delta_{\mathrm{u}}$ is respectively the construction pretension, the slip load, the slip displacement, ultimate loadcarrying capacity, the peak displacement and the ultimate displacement. The slip displacement is defined as follows: for the specimen with bolt pretension, the displacement difference between before and after the specimen slips is regarded as the slip displacement; while for the specimen without pretension, take the displacement corresponding to the load of $10 \mathrm{kN}$. Herein, the peak displacement and the ultimate displacement do not contain the slip displacement. For the bolt shear failure specimens, the ultimate displacement is the same as the peak displacement.

\subsection{Analysis of test results}

\subsubsection{Influence of steel thickness}

In this test, the specimens of A-12.9-3, A-12.9-1, and A-12.9-4 were manufactured by Q345 steel with nominal thicknesses of $10 \mathrm{~mm}, 14 \mathrm{~mm}$ and 16 $\mathrm{mm}$ respectively. Splitting failure occurred in all the three specimens, and their load-carrying capacity and deformation are listed in Table 8 . The load-carrying capacity of the specimens increases as the thickness of the test plate increases, while the ratio of the load-carrying capacity to the product of thickness and the ultimate strength of the test plate remain constant, i.e. the load-carrying capacity of the specimens is proportional to the product of the thickness and the steel tensile strength of the test plate. 
Table 7

Test results

\begin{tabular}{|c|c|c|c|c|c|c|c|}
\hline Specimen & $P_{\mathrm{c}}(\mathrm{kN})$ & $F_{\mathrm{S}}(\mathrm{kN})$ & $\Delta_{\mathrm{s}}(\mathrm{mm})$ & $F_{\mathrm{u}}(\mathrm{kN})$ & Failure mode & $\Delta_{\mathrm{p}}(\mathrm{mm})$ & $\Delta_{\mathrm{u}}(\mathrm{mm})$ \\
\hline A-12.9-1 & 203 & 140.8 & 2.63 & 348.0 & SPF & 16.44 & 28.02 \\
\hline A-12.9-1n & 0 & - & 4.20 & 342.4 & SPF & 18.54 & 31.00 \\
\hline A-12.9-2 & 203 & 185.8 & 2.55 & 392.0 & SPF & 13.67 & 32.39 \\
\hline A-12.9-3 & 208 & 155.7 & 3.59 & 221.4 & SPF & 21.10 & 36.15 \\
\hline A-12.9-4 & 203 & 154.1 & 1.54 & 426.0 & SPF & 18.25 & 30.99 \\
\hline A-12.9-5 & 203 & 171.3 & 1.06 & 369.5 & SPF & 14.83 & 24.40 \\
\hline A-12.9-5n & 0 & - & 3.30 & 342.4 & SPF & 21.30 & 31.68 \\
\hline A-12.9-6 & 203 & 162.5 & 1.97 & 362.8 & SPF & 17.06 & 27.24 \\
\hline A-12.9-6n & 0 & - & 2.98 & 365.8 & SPF & 21.71 & 29.31 \\
\hline A-12.9-7 & 203 & 151.6 & 3.95 & 249.0 & $\mathrm{TF}$ & 12.42 & 23.16 \\
\hline A-12.9-7n & 0 & - & 2.10 & 250.4 & $\mathrm{TF}$ & 14.70 & 24.58 \\
\hline A-12.9-8 & 203 & 169.2 & 3.42 & 303.4 & SPF & 15.89 & 25.29 \\
\hline A-12.9-8n & 0 & - & 4.26 & 304.6 & SPF & 17.44 & 29.07 \\
\hline A-12.9-9 & 203 & 163.8 & 3.46 & 457.0 & SPF & 29.34 & 42.13 \\
\hline A-12.9-9n & 0 & - & 3.16 & 456.5 & SPF & 29.56 & 35.40 \\
\hline B-12.9-3 & 203 & 298.8 & 2.77 & 670.0 & SPF & 20.14 & 28.77 \\
\hline B-12.9-3n & 0 & - & 4.08 & 682.5 & SPF & 23.82 & 32.81 \\
\hline C-12.9-1 & 203 & 271.8 & 1.86 & 438.0 & NF & 8.74 & 12.68 \\
\hline C-12.9-1n & 0 & - & 3.81 & 447.0 & NF & 14.12 & 17.95 \\
\hline C-12.9-2 & 203 & 308.0 & 2.59 & 585.0 & $\mathrm{NF}$ & 10.60 & 14.92 \\
\hline C- $12.9-2 n$ & 0 & - & 3.44 & 606.0 & $\mathrm{NF}$ & 18.59 & 21.78 \\
\hline C-12.9-3 & 203 & 417.5 & 2.39 & 684.5 & SPF & 17.08 & 28.42 \\
\hline C-12.9-3n & 0 & - & 3.29 & 674.0 & SPF & 22.91 & 29.96 \\
\hline C-12.9-4 & 203 & 320.0 & 2.29 & 483.5 & $\mathrm{TF}$ & 9.18 & 17.73 \\
\hline C-12.9-4n & 0 & - & 3.69 & 418.2 & SPF & 12.84 & 22.15 \\
\hline C-12.9-5 & 201 & 348.2 & 2.92 & 557.5 & SPF & 12.63 & 21.39 \\
\hline C-12.9-5n & 0 & - & 3.84 & 560.5 & SPF & 13.39 & 21.37 \\
\hline C-12.9-6 & 203 & 290.0 & 2.17 & 720.0 & NF & 24.62 & 27.12 \\
\hline C-12.9-6n & 0 & - & 3.48 & 714.5 & NF & 24.74 & 27.28 \\
\hline A-10.9-1 & 110 & 97.0 & 1.74 & 278.4 & $\mathrm{SF}$ & 10.84 & 10.84 \\
\hline A-10.9-1n & 0 & - & 2.26 & 264.4 & $\mathrm{SF}$ & 9.77 & 9.77 \\
\hline A-10.9-2 & 168 & 135.4 & 1.50 & 369.2 & SPF & 17.80 & 31.75 \\
\hline A-10.9-2n & 0 & - & 3.76 & 388.8 & $\mathrm{BF}$ & 20.45 & 33.29 \\
\hline B-10.9-1 & 110 & 184.0 & 1.64 & 544.5 & $\mathrm{SF}$ & 14.18 & 14.18 \\
\hline B-10.9-1n & 0 & - & 4.05 & 526.5 & $\mathrm{SF}$ & 14.09 & 14.09 \\
\hline B-10.9-2 & 168 & 229.0 & 2.78 & 683.0 & SPF & 22.20 & 31.76 \\
\hline B-10.9-2n & 0 & - & 3.80 & 665.0 & SPF & 24.04 & 39.10 \\
\hline C-10.9-1 & 105 & 274.4 & 2.53 & 593.0 & $\mathrm{SF}$ & 15.71 & 15.71 \\
\hline C-10.9-1n & 0 & - & 2.70 & 516.0 & $\mathrm{SF}$ & 9.91 & 9.91 \\
\hline C-10.9-2 & 105 & 197.2 & 1.77 & 558.0 & SF & 11.99 & 12.36 \\
\hline C-10.9-2n & 0 & - & 3.90 & 497.5 & $\mathrm{SF}$ & 6.64 & 6.64 \\
\hline C-10.9-3 & 168 & 335.6 & 1.58 & 613.5 & NF & 14.89 & 19.48 \\
\hline C-10.9-3n & 0 & - & 3.29 & 587.5 & NF & 22.91 & 27.29 \\
\hline C-10.9-4 & 168 & 315.0 & 2.59 & 682.5 & SPF & 17.99 & 27.89 \\
\hline C-10.9-4n & 0 & - & 3.71 & 715.0 & SPF & 23.76 & 29.33 \\
\hline
\end{tabular}

\subsubsection{Influence of bolt specifications}

12.9 M20, 10.9 M20 and 10.9 M16 high-strength bolts were used in this test. The statistical data in Table 6 shows that the failure modes of the specimens set with different bolts are different. The bolts specifications significantly affect the failure mode of the specimens, primarily controlling the occurrence of the shear failure modes of the bolts. All specimens with bolts of 10.9 M16 failed resulted in bolt shear in this test.

Table 9 shows the comparison of the load-carrying capacity and deformation of specimens with different high-strength bolts. The difference in load-carrying capacity $\left|\Delta F_{\mathrm{u}}\right|$ shown in Table 9 is small, and the maximum ratio $\left|\Delta F_{\mathrm{u}}\right|$ to the load-carrying capacity $F_{\mathrm{u}}$ is $6.1 \%$. The grade of bolt shows an unobvious influence on the load-carrying capacity and deformation of the specimen with splitting failure and net cross-section failure. 
Table 8

Effect of plate thickness on bearing capacity and deformation of the specimens

\begin{tabular}{cccccc}
\hline Specimen & $t(\mathrm{~mm})$ & $f_{\mathrm{u}}(\mathrm{MPa})$ & $F_{\mathrm{u}}(\mathrm{kN})$ & $F_{\mathrm{u}} / f_{\mathrm{u}} t$ & $\Delta_{\mathrm{p}}(\mathrm{mm})$ \\
\hline A-12.9-3 & 9.76 & 484.81 & 221.4 & 0.0468 & 21.10 \\
A-12.9-1 & 14.53 & 526.73 & 348.0 & 0.0455 & 16.44 \\
A-12.9-4 & 16.01 & 586.54 & 426.0 & 0.0454 & 18.25 \\
\hline
\end{tabular}

Table 9

Bearing capacity and deformation of different bolt specimens

\begin{tabular}{|c|c|c|c|c|c|}
\hline Specimen & Bolt & Failure mode & $F_{\mathrm{u}}(\mathrm{kN})$ & $\left|\Delta F_{\mathrm{u}}\right|(\mathrm{kN})$ & $\Delta_{\mathrm{p}}(\mathrm{mm})$ \\
\hline A-12.9-1 & $12.9 \mathrm{M} 20$ & \multirow{2}{*}{ SPF } & 348.0 & \multirow{2}{*}{21.2} & 16.44 \\
\hline A-10.9-2 & $10.9 \mathrm{M} 20$ & & 369.2 & & 17.80 \\
\hline B-12.9-3 & $12.9 \mathrm{M} 20$ & \multirow{2}{*}{ SPF } & 670.0 & \multirow{2}{*}{13.0} & 20.14 \\
\hline B-10.9-2 & $10.9 \mathrm{M} 20$ & & 683.0 & & 22.20 \\
\hline C-12.9-3 & $12.9 \mathrm{M} 20$ & \multirow{2}{*}{ SPF } & 684.5 & \multirow{2}{*}{2.0} & 17.08 \\
\hline C-10.9-4 & $10.9 \mathrm{M} 20$ & & 682.5 & & 17.99 \\
\hline C-12.9-2 & $12.9 \mathrm{M} 20$ & \multirow[t]{2}{*}{$\mathrm{NF}$} & 585.0 & \multirow[t]{2}{*}{28.5} & 7.60 \\
\hline C-10.9-3 & $10.9 \mathrm{M} 20$ & & 613.5 & & 14.89 \\
\hline
\end{tabular}

\subsubsection{Influence of bolt pretension}

In this test, the influence of bolt pretension on the load-carrying capacity, stiffness and deformation of specimens with various failure modes was primarily studied. Fig. 11 shows the effect of pretension on the load-carrying capacity of the specimens with tearout failure, splitting failure, net cross-section failure and bolt shear failure. Two specimens with the same geometric dimensions but differ in whether pretension was applied or not are defined as one pair. The naming of the specimen pair adopted the name of the specimen with bolt pretension in this pair. For example, the two specimens C-10.9-4 and C-345-10.9-4n were identified as a pair of C-10.9-4. As shown in Fig. 11, the pretension has no significant effect on the load-carrying capacity of the specimens with tearout failure, splitting failure and net cross-section failure. The maximum deviation of the ultimate load-carrying capacity of the two specimens in the same pair is only $5.18 \%$. When the specimens with the above three failure modes close to failing, the slippage of the specimen had been completed already and the surface of each plate became smoother, meanwhile, the pretension decreased due to the deformation. Accordingly, the friction between the cover plates and the test plate of the specimens with pretension was relatively small and the influence of the pretension on the ultimate load-carrying capacity of the specimens is insignificant. In another word, the influence of the bolt pretension on the ultimate load-carrying capacity of the specimens that failed with tearout failure, splitting failure and net cross-section failure can be neglected. However, the pretension shows a significant effect on the loadcarrying capacities of the specimens subjected to bolt shear failure. The loadcarrying capacities of the specimens with pretension are higher than that of the specimens without it. The pretension improved the load-carrying capacity of the specimens with bolt shear failure. Table 10 lists the relationship between the load-carrying capacity and the slip load of the specimen pairs in which the bolt shear failure occurred, where the $F_{\mathrm{u}, \mathrm{Y}}$ and $F_{\mathrm{u}, \mathrm{N}}$ is the ultimate load-carrying capacity of the specimen with or without preload respectively. The pretension could increase the load-carrying capacity of the connections, and the improvement is approximately $9.8 \% \sim 30.7 \%$ of the slip load but with a relatively large deviation range.

\section{Table 10}

Increases of load-bearing capacity and slip load of specimens with bolt shear failure

\begin{tabular}{cccccc}
\hline \multicolumn{2}{c}{ Specimen } & $F_{\mathrm{u}, \mathrm{Y}}(\mathrm{kN})$ & $F_{\mathrm{u}, \mathrm{N}}(\mathrm{kN})$ & $F_{\mathrm{S}}(\mathrm{kN})$ & $\left(F_{\mathrm{u}, \mathrm{Y}}-F_{\mathrm{u}, \mathrm{N}}\right) / F_{\mathrm{s}}$ \\
\hline A-10.9-1 & A-10.9-1n & 278.4 & 264.4 & 97.0 & 0.144 \\
B-10.9-1 & B-10.9-1n & 544.5 & 526.5 & 184.0 & 0.098 \\
C-10.9-1 & C-10.9-1n & 593.0 & 516.0 & 274.4 & 0.281 \\
C-10.9-2 & C-10.9-2n & 558.0 & 497.5 & 197.2 & 0.307 \\
\hline
\end{tabular}

Fig. 12 shows the load-displacement curves of some specimens with different failure modes. For the specimens in the same pair, the two specimens have similar geometric dimensions but differ in the presence or absence of bolt pretension. To facilitate the comparison, the load-displacement curves of the specimens with the tearout failure, splitting failure and net cross-section failure specimens were plotted on the principle that the peak displacements of the two specimens are equal. While since the pretension affects the load-carrying capacity of the bolt shear failure specimens, the load-displacement curves of the bolt shear failure specimens were drawn according to the rule that make the displacement corresponding to the load-bearing capacity of the specimen with pretension equal to that of the specimen without pretension.

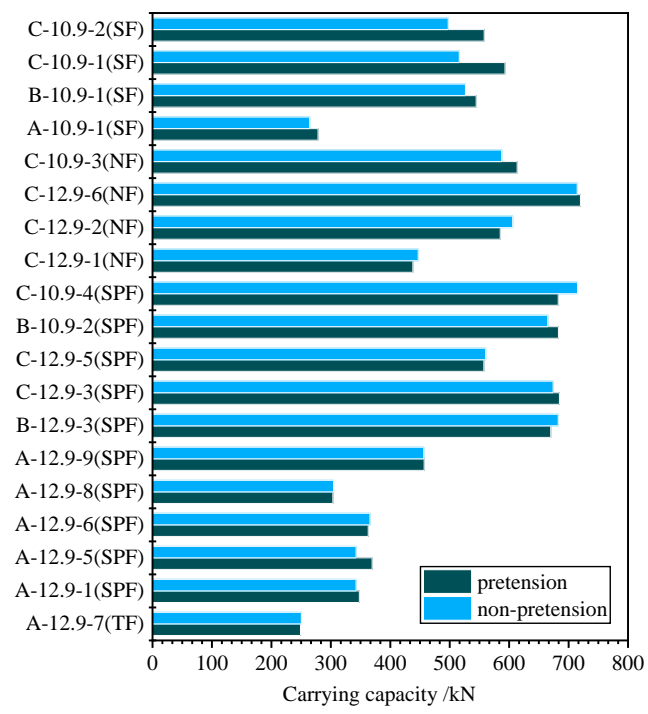

Fig. 11 Effect of pretension on bearing capacity of specimens with different failure modes

As shown in Fig. 12 (a) to Fig. 12 (c), the stiffnesses of specimens with pretension were larger than that of the non-pretension specimens at the friction stage and the initial stage of the bolt bar extrusion. However, as the load increased, the bearing stress of the bolt increased, the bolt hole deformation increased also, and the stiffness of the pretension specimens became gradually smaller. The stiffness change segment was identified in the diagram, the descending was rapid; and in the segment, the stiffness was less than that of the non-pretension specimen. This phenomenon can be explained as follows: in the initial stage of loading the bolt pretension specimens, there was little pretension loss, and the friction causes the stiffness of the specimen to be larger than that of the non-pretension specimen. With load increased, the bolt hole extrusion deformation and the bending deformation of the bolt bar were increased also, and the bolt pretension loss was accumulated. Meanwhile, the contact surface became smoother because of slippage. Owing to the above two reasons, the friction of the pretension specimens was decreasing in the period, the bolt hole bearing load was increased, the deformation of the bolt hole was aggravated, the displacement of specimens was increased, and the stiffness of the specimens was decreased. The bolt pretension has a certain influence on the shear connections with bolt shear failure before the failure, as shown in Fig. 12(d). When the load reaches the ultimate load-carrying capacity of the non-pretension specimens, there is no obvious stiffness change segment in the bolt pretension specimens. The stiffness tended to be stable when approaching failure and is lower than that of specimens without bolt pretension.

\subsubsection{Influence of geometrical dimensions}

The geometrical limitations for shear connections are specified in the European steel structure design code (Eurocode 3) and the American steel structure specification (AISC360-10). Moreover, geometrical dimension parameters are also involved in the bearing capacity formulas in the above code or specification. The above two aspects reflect the important role of geometrical dimensions in the behaviour of the shear connection.

Fig. 13 and Fig. 14 show the relationship between load-carrying capacity and end distance and that between load-carrying capacity and edge distance respectively. To facilitate the analysis, dimensionless coordinate systems were adopted. For the vertical axis, the load-carrying capacity of the specimen was nondimensionalized according to the corresponding failure modes. In the dimensionless method, define the bearing stress ratio $\alpha_{\mathrm{b}}$, the net cross-section stress ratio $\alpha_{\mathrm{n}}$ and the bolt shear stress ratio $\alpha_{\mathrm{s}}$, which can be calculated by Eq (2) to (4). While the abscissa was nondimensionalized by using the index of the ratio of the end distance to the bolt hole diameter. 
$\alpha_{\mathrm{b}}=\frac{F_{\mathrm{u}}}{f_{\mathrm{u}} d t}$

$\alpha_{\mathrm{n}}=\frac{F_{\mathrm{u}}}{A_{\mathrm{n}} f_{\mathrm{u}}}$

$\alpha_{\mathrm{s}}=\frac{F_{\mathrm{u}}}{A f_{\mathrm{u}}^{\mathrm{b}}}$

where $A_{\mathrm{n}}$ is the net sectional area of the test plate, and $A$ is the shear crosssectional area of the bolt (when the threaded section is in shearing, it shall be calculated based on the effective area of the threaded section $A_{\mathrm{e}}$ )

For the tearout failure and splitting failure specimens, as shown in Fig. 13(a) and Fig. 13(b), in the range of the end distance $\left(1.35 d_{0}-2.67 d_{0}\right)$ in this test, as the end distance increases, the failure mode of the specimens transformed from tearout failure to splitting failure. For the A-series specimens with splitting failure, the bearing stress ratio increased substantially in a linear manner. For the net cross-section failure and the bolt shear failure specimens, as shown in Fig. 13(c) and (d), the load-carrying capacity of the specimens shows little relation with the change in the end distance. The net cross-section stress ratio of the specimen with the net cross-section failure is between 1.00 and 1.10 , and the bolt shear stress ratio of the bolt shear failure specimen is almost greater than $1 / \sqrt{3}$, i.e. 0.577 .

As shown in Fig. 14(a) and Fig. 14(b), in the edge distance range $\left(1.77 d_{0^{-}}\right.$ $2.78 d_{0}$ ) in this test, the bearing stress ratio of the tearout failure and splitting failure specimens did not change significantly. There is no obvious correlation between the bearing stress ratio and edge distance. For the net cross-section failure specimens, the net cross-section stress ratio is distributed between 1.00 and 1.10. As shown in Fig. 14(c), the net section stress ratio has little relationship with the edge distance. In fact, when using Eq. (3) to calculate the net cross-section stress ratio, the influence of the edge distance had already been considered, indicating that the load-carrying capacity has a significant positive correlation with the edge distance. As shown in Fig. 14(d), the bolt shear stress of the bolt shear failure specimen is greater than $1 / \sqrt{3}$, i.e. 0.577 , which shows an unobvious correlation with the edge distance.

\section{Comparison with specification calculation results}

\subsection{Specification calculation results}

There are different geometric requirements for bolted shear connections in different codes, standards and specifications ${ }^{[25-27]}$. The following analysis of different specifications was based on the test data of the specimens that meet the geometric requirements of the corresponding specifications. The number of specimens that meet the geometric requirements of different specifications was counted according to failure mode, as shown in Table 11. Instead of dividing the failure modes into tearout failure, splitting failure, and pure bearing failure, Eurocode 3 and AISC360-10 put these three failure modes into one category, i.e. bearing failure. Besides, GB50017-2017 sets strict geometric requirements to avoid the occurrence of tearout failure and holds that splitting failure and pure bearing failure are included in bearing failure. Therefore, to facilitate the comparison among various calculation methods in various specifications, tearout failure, splitting failure and pure bearing failure of the specimens were collectively referred to as bearing failure in the following discussion.

Table 11

The quantity of specimens meets the requirements for various specifications

\begin{tabular}{cccc}
\hline Failure mode & GB50017-2017 & Eurocode 3 & AISC360-10 \\
\hline BF & 21 & 29 & 29 \\
NF & 2 & 6 & 6 \\
SF & 8 & 8 & 8 \\
Total & 31 & 43 & 43 \\
\hline
\end{tabular}

The calculation methods in the GB 50017-2017, EC3 and AISC 360-10 are listed in Table 12. The calculated resistances and the predicted failure modes according to the three specifications are listed in Table 13. All parameters used for calculation are the actual, and the partial safety factor is not included. In Table 13, the calculation result with the symbol "**" indicates that the specimen does not meet the geometric requirements of the corresponding specification. $F_{\mathrm{u}, \mathrm{CH}}, F_{\mathrm{u}, \mathrm{EC}}, F_{\mathrm{u}, \mathrm{AISC}, 1}$ and $F_{\mathrm{u}, \mathrm{AISC}, 2}$ represent the resistance calculated according to GB50017-2017, Eurocode 3, AISC360-10 method 1 and AISC36010 method 2 respectively. And the calculation resistance took the minimum of calculated resistance of bolts against shear force, bearing capacity and resistance of net cross-section against tension. Meanwhile, the failure mode refers to the mode corresponding to the calculation resistance.

The shear capacity of the connection is based on the load-carrying capacity of a single bolt. But the calculation principles for the resistance of bolts against shear force are different among the three specifications. The shear capacity of the connection is defined as the sum of the load-carrying capacity of a single bolt in GB50017-2017 and AISC360-10. While in Eurocode 3, if the shear capacity of each bolt in the connection is greater than its corresponding bearing capacity, the shear capacity of the connection is the sum of the bearing capacity of each bolt, otherwise it should be represented as the value obtained by multiplying the minimum load-carrying capacity of any single bolt by the number of bolts.

\subsection{Comparison of load-carrying capacity}

The comparison of the experimental resistance with its corresponding calculated value according to the three specifications were drawn in Fig. 15 and the quantitative comparison was presented in Table 14. In Table 14, the average values of the ratio of the test load-carrying capacity to the calculated value of each specification were listed according to the actual failure mode of the specimens, and the standard deviation of the average values was also calculated.

As shown in Table 14, the ratio of test load-carrying capacity to the calculated value of each specification was averaged and found all of that were not less than 1.0, with GB50017-2017 and Eurocode 3 being conservative and AISC360-10 method 2 being the closest to the experimental results. Except for the calculated resistances using AISC360-10 method 2 for the specimens with bearing failure are slightly higher than the experimental results, the calculated resistances using the methods in other specifications for all failure modes are less than the experimental results.

For the specimens with bearing failure, Eurocode 3 is the most conservative specification and GB50017-2017 is second to it. On the contrary, AISC360-10 method 2 overestimates the resistance. For the specimens with net cross-section failure, the principles in the three different specifications are different. The failure criteria adopted by GB GB50017-2017 is the yield of the net crosssection, which makes it the most conservative specification of the three. While Eurocode 3 and AISC360-10 take the minimum of the resistances of gross section yield and net section fracture as failure criteria. Besides, a safety factor of 0.9 is adopted for net section fracture in Eurocode 3, while the net crosssection fracture is directly adopted in AISC360-10 without a safety factor, which results in AISC360-10 being most close to the capacity obtained by experiment. For the specimens with bolt shear failure, GB50017-2017 is the most conservative, followed by Eurocode 3 and AISC360-10.

\subsection{Failure mode comparison}

The gap between the load-carrying capacity obtained by the experiment and the calculation according to specifications reflects the degree of "safety reserve" of each specification for different failure modes. But it is at the cost of the accuracy of the prediction of the failure mode.

Table 15 lists the accuracy of the failure mode prediction of each specification. The failure mode in the table refers to the actual failure mode of the specimens. In general, the prediction using the AISC360-10 method 1 is the most accurate, and the prediction accuracy of the failure mode of the specimens in this test reaches $95.4 \%$.

As to each failure mode, for the specimens with bearing failure, except for AISC360-10 method 2, the other three methods can predict the failure mode well. For the specimens with net cross-section failure, AISC360-10 method 2 shows better prediction accuracy among the four methods. And for the specimens with bolt shear failure, AISC360-10 method 1 can predict the failure mode well.

The large difference in the prediction accuracy of each specification for different failure modes is caused by the difference in the "safety reserve" among the bearing capacity, bolt shear capacity and net cross-section capacity.

As shown in Table 14, GB50017-2017 has the highest safety factor for bolt shear failure, but correspondingly, it cannot output an accurate prediction for bolt shear failure, which is also presented zero accuracies in Table 15. Similarly, Eurocode 3 owns the best prediction for bearing failure. AISC360-10 method 1 has a good prediction for bearing failure and bolt shear failure, and method 2 has a good prediction for the net section failure and bolt shear failure. In general, the prediction accuracy of the failure mode of AISC360-10 method 1 shows the best in the four. Generically, the safety reserve of bearing capacity, bolt shear capacity and net cross-section capacity in the code formula has a decisive influence on the accuracy of the code formula for predicting the failure mode. 


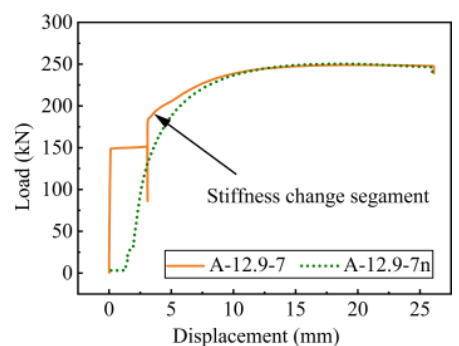

(a) Tearout failure

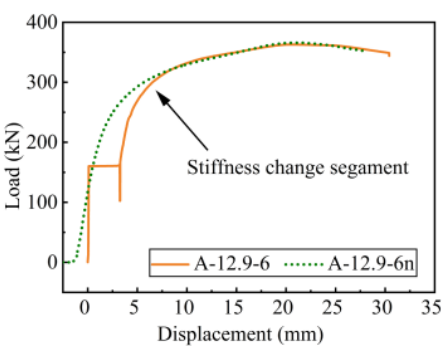

(b) Splitting failure

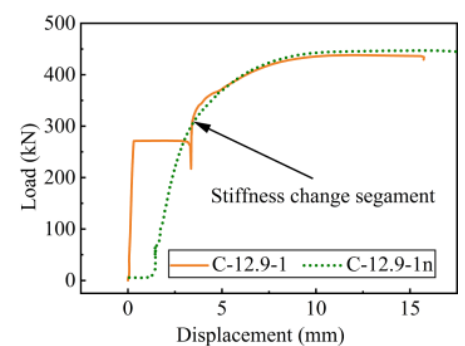

(c) Net cross-section failure

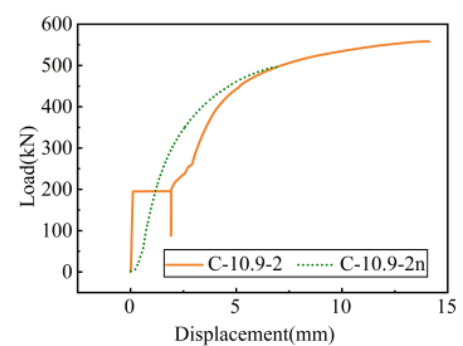

(d) Bolt shear failure

Fig. 12 Effect of pretension on the stiffness of specimens with different failure modes

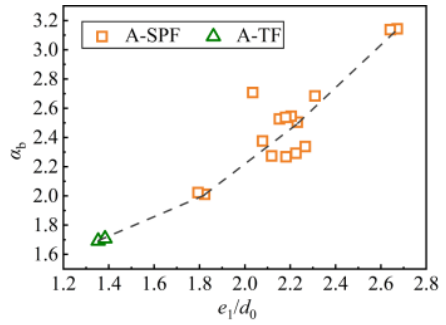

(a) A-series tearout and splitting specimens

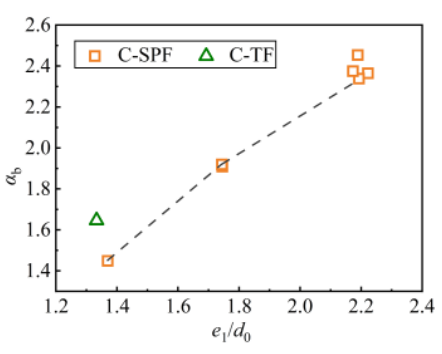

(b) C-series tearout and splitting specimens

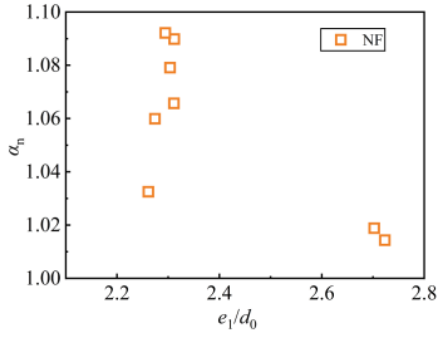

(c) Net cross-section failure

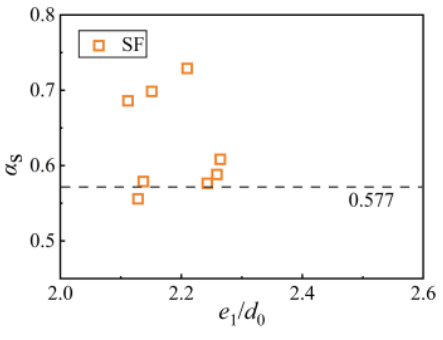

(d) Bolt shear failure

Fig. 13 Effect of end distance on bearing capacity of specimens

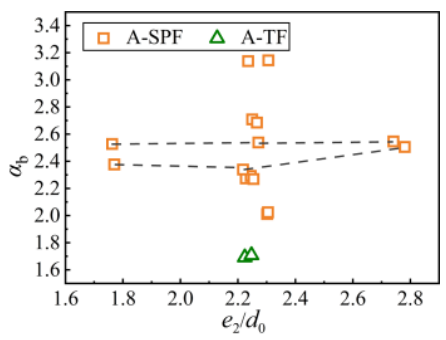

(a) A-series tearout and splitting specimens

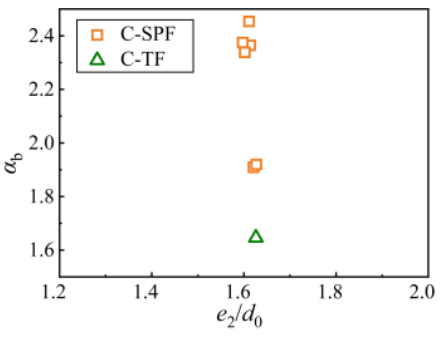

(b) C-series tearout and splitting specimens

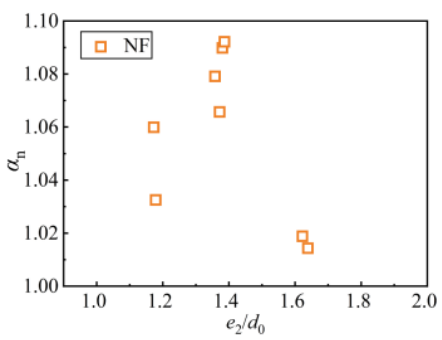

(c) Net cross-section failure

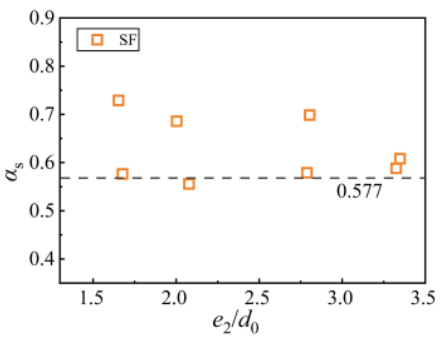

(d) Bolt shear failure

Fig. 14 Effect of edge distance on bearing capacity of specimens

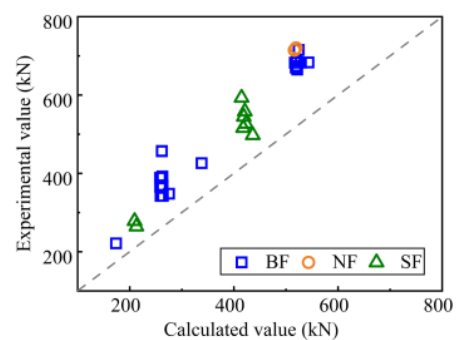

(a) GB50017-2017

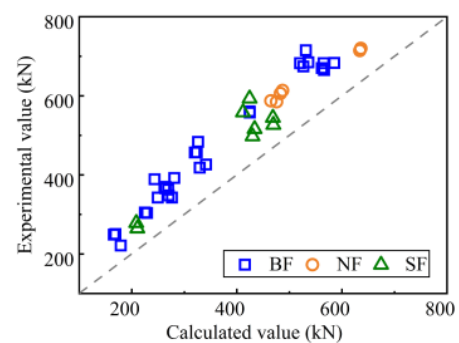

(b) EC 3

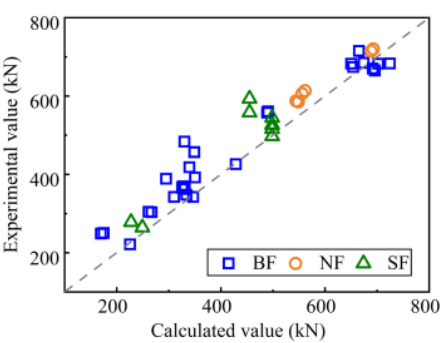

(c) AISC 360-10 method 1

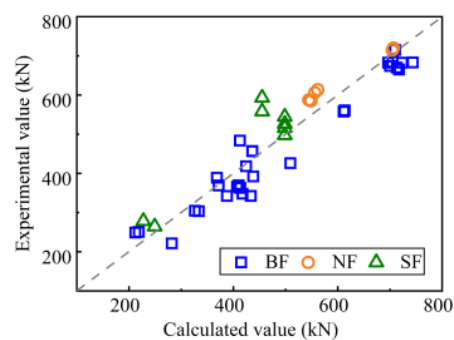

(d) AISC 360-10 method 2

Fig. 15 Comparison between experimental resistance and calculated value

\section{Discussion on the applicability of the code formula for B-series specimens}

For the B-series specimens, the bearing resistances for the two bolts with different end distances were calculated and summed when calculating the bearing resistance according to Eurocode 3 and AISC360-10, which means the deformation at the bolt hole was not taken into consideration. However, the peak displacements of the specimens with different end distances are different when the ultimate bearing capacity is achieved, which means there are different displacement requirements for specimens with different end distances to get their ultimate bearing capacities.

As to the specimen with two bolts parallel to the force, shown as Fig.16, whether the bearing resistance of the specimen (assuming that net section failure and bolt shear failure do not occur) is a simple summation of the bearing resistance of the inner bolt and outer bolt is worth discussing.

If the inner bolt and outer bolt reached their respective ultimate bearing capacity simultaneously or if the outer bolt had sufficient ductility to maintain the ultimate bearing capacity and the inner bolt reaching its ultimate bearing capacity before the outer bolt fails, the connection bearing resistance could be obtained by simply summing the bearing resistance of the two bolts. However, this is not the case in reality. The end distances of the four A-series specimens in Fig. 17 vary from 31.17 to $59.30 \mathrm{~mm}$, and the peak displacements of the three specimens that failed with splitting are significantly different. The bearing capacity of the specimens with a large end distance is significantly lower than its ultimate bearing capacity at the deformation that corresponds to the specimen with a small end distance reaches its ultimate bearing capacity. Vice versa, the bearing capacity of the specimens with a small end distance has started to decline or already failed at the deformation that corresponds to the specimens with a large end distance achieves its ultimate bearing capacity. The loaddisplacement curve of specimen B-12.9-3n is drawn in Fig. 17, which indicates the peak displacement is between the peak displacement of specimen A-12.9$6 \mathrm{n}$ and the peak displacement of A-12.9-9n.

Table 16 lists the experimental bearing capacity and the corresponding calculated values of a B-series specimen with bearing failure. For individual bolts in the B-series specimen, the calculated capacities of the two bolts are different using the methods in Eurocode 3 and AISC360-10. The experimental bearing capacity of the $\mathrm{B}$-series specimens is approximately twice that of the Aseries specimens with similar end distances. For B-series specimens in this 
paper, when the outer bolt is approaching failure, the resistance of the two bolts in the B-series specimens can be considered evenly distributed. In another word, the bearing capacities of the inner bolt and the outer bolt are almost equal, and the bearing capacity of the connection can be considered as twice that of the outer bolt. However, for the shear connection of two bolts with a small end distance and a binger pitch parallel to the force direction, the displacement requirement to achieve the ultimate bearing capacity is different for two bolts, so that the ultimate bearing capacity cannot be reached simultaneously. Further, the connection bearing capacity obtained by the simple summation method according to Eurocode 3 and AISC360-10 will be significantly higher than the actual bearing capacity of the connection. Therefore, for the shear connection with two bolts parallel to the force, when there is a large difference between the end distance and pitch, the safety of the bearing capacity calculated by the methods in Eurocode 3 and AISC360-10 will be significantly lower than the shear connection with a single bolt. And when the difference between the end distance and pitch is larger, an unsafe situation may occur. GB 50017-2017 sets stricter geometric requirements for shear connections. The influence of geometrical dimensions on the bearing capacity of bolts is not a design consideration and assumes that the bolts are evenly stressed, which agrees with the performance of the B-series specimens in this test.

Table 12

Calculation methods in various specifications

\begin{tabular}{|c|c|c|c|}
\hline Specification & Bearing resistance & Net cross-section resistance & Bolt shear resistance \\
\hline $\begin{array}{l}\text { GB50017- } \\
2017\end{array}$ & where, & $N=A_{\mathrm{n}} f_{\mathrm{y}}$ & $N_{v}^{b}=n_{v} \frac{\pi d^{2}}{4} f_{v}^{b}$ \\
\hline \multirow{8}{*}{2017} & $d$ is bolt shank diameter; & $A_{\mathrm{n}}$ is the net sectional area; & where, \\
\hline & $\sum t$ is the lesser sum of thickness of the connected plies bearing in & $f_{\mathrm{y}}$ is the yield strength of steel. & $n_{v}$ is the number of shear plane; \\
\hline & the same direction; & & $d$ is bolt shank diameter, and when the threaded \\
\hline & $f_{c}^{b}$ is the design value of bearing strength of the bolt; & & section is in shearing, the design value of shear \\
\hline & And $f_{c}^{b}=1.26 f_{u}$, where $f_{u}$ is the ultimate strength of steel. & & capacity shall be calculated based on the effective \\
\hline & & & area of the threaded section. \\
\hline & & & $f_{c}^{b}$ is the design value of shear strength of the bolt; \\
\hline & & & And $f_{v}^{b}=0.3 f_{u}^{b}$, where $f_{u}^{b}$ is the ultimate \\
\hline
\end{tabular}

EC3 $F_{b, R d}=\frac{k_{1} \alpha_{b} f_{u} d t}{\gamma_{M 2}}$

where,

$\alpha_{b}$ is the smallest of $\alpha_{d}, \frac{f_{u b}}{f_{u}}$ or 1.0 ;

in the direction of load transfer:

for end bolts: $\alpha_{d}=\frac{p_{1}}{3 d_{0}}$; for the inner bolts: $\alpha_{d}=\frac{p_{1}}{3 d_{0}}-\frac{1}{4}$.

perpendicular to the direction of load transfer:

for the edge bolts: $k_{1}=\min \left(2.8 \frac{e_{2}}{d_{0}}-1.7,2.5\right)$; for inner bolts:

$k_{1}=\min \left(1.4 \frac{p_{2}}{d_{0}}-1.7,2.5\right)$.

and where $f_{u}$ is the ultimate strength of steel; $\gamma_{M 2}$ is the safety

factor, which is $1.25 ; d$ and $d_{0}$ are the diameter of bolt and bolt

hole respectively.

AISC 360- Method 1: When deformation at the bolt hole at service load is a

10

design consideration.

$$
R_{n 1}=1.2 \phi l_{c} t F_{u} \leq 2.4 \phi d t F_{u}
$$

Method 2: When deformation at the bolt hole at service load is not a design consideration.

$$
R_{n 2}=1.5 \phi l_{c} t F_{u} \leq 3.0 \phi d t F_{u}
$$

where,

$l_{c}$ is the clear distance;

$t$ is the thickness of connected material.

$\phi$ is the safety factor;

$F_{u}$ is the specified minimum tensile strength of the connected

material;

$d$ is the nominal fastener diameter
$N=\min \left(0.9 A_{\mathrm{n}} f_{\mathrm{u}}, A f_{\mathrm{y}}\right)$

where,

$A_{\mathrm{n}}$ is the net sectional area;

$A$ is the gross sectional area;

$f_{\mathrm{y}}$ is the yield strength of steel;

$f_{u}$ is the ultimate strength of steel.

$$
F_{v, R d}=\frac{\alpha_{v} f_{u b} A}{\gamma_{M 2}}
$$

where the shear plane passes through the threaded portion of the bolt ( $A$ is the tensile stress area of the bolt $A_{\mathrm{s}}$ ):

for classes 4.6, 5.6 and 8.8: $\alpha_{v}=0.6$;

for classes 4.8, 5.8, 6.8 and 10.9: $\alpha_{v}=0.5$;

while where the shear plane passes through the unthreaded portion of the bolt (A is the gross crosssection of the bolt): $\alpha_{v}=0.6$.

and $\gamma_{M 2}$ is the safety factor, $f_{u b}$ is the ultimate tensile strength.

$$
N=\min \left(A_{\mathrm{n}} f_{\mathrm{u}}, A f_{\mathrm{y}}\right)
$$

$$
R_{n 1}=\phi F_{n v} A_{b}
$$

where,

$A_{\mathrm{n}}$ is the net sectional area;

$A$ is the gross sectional area;

$f_{\mathrm{y}}$ is the yield strength of steel;

$f_{u}$ is the ultimate strength of steel. where,

$\phi$ is the safety factor;

$F_{n v}$ is the nominal shear stress;

$A_{b}$ is the nominal unthreaded body area of bolt or threaded part. 
Table 13

Comparison between test results and calculated values

\begin{tabular}{|c|c|c|c|c|c|c|c|c|c|c|c|c|c|c|}
\hline \multirow[b]{2}{*}{ Specimen } & \multirow{2}{*}{$\begin{array}{l}\text { Actual } \\
\text { failure } \\
\text { mode }\end{array}$} & \multirow{2}{*}{$\begin{array}{l}F_{\mathrm{u}} \\
\mathrm{kN}\end{array}$} & \multicolumn{3}{|c|}{ GB 50017-2017 } & \multicolumn{3}{|c|}{ Eurocode 3} & \multicolumn{3}{|c|}{ AISC $360-10$ method 1} & \multicolumn{3}{|c|}{ AISC $360-10$ method 2} \\
\hline & & & $\begin{array}{l}\text { Failure } \\
\text { mode }\end{array}$ & $\begin{array}{l}F_{\mathrm{u}, \mathrm{CH}} \\
(\mathrm{kN})\end{array}$ & $\frac{F_{\mathrm{u}}}{F_{\mathrm{u}, \mathrm{CH}}}$ & $\begin{array}{l}\text { Failure } \\
\text { mode }\end{array}$ & $\begin{array}{l}F_{\mathrm{u}, \mathrm{EC}} \\
(\mathrm{kN})\end{array}$ & $\frac{F_{\mathrm{u}}}{F_{\mathrm{u}, \mathrm{EC}}}$ & $\begin{array}{l}\text { Failure } \\
\text { mode }\end{array}$ & $\begin{array}{c}F_{\mathrm{u}, \mathrm{AISC}, 1} \\
(\mathrm{kN})\end{array}$ & $\frac{F_{\mathrm{u}}}{F_{\mathrm{u}, \mathrm{AISC}, 1}}$ & $\begin{array}{l}\text { Failure } \\
\text { mode }\end{array}$ & $\begin{array}{c}F_{\mathrm{u}, \mathrm{AISC}, 2} \\
(\mathrm{kN})\end{array}$ & $\frac{F_{\mathrm{u}}}{F_{\mathrm{u}, \mathrm{AISC}, 2}}$ \\
\hline A-12.9-1 & $\mathrm{BF}$ & 348.0 & $\mathrm{BF}$ & 275.52 & 1.26 & $\mathrm{BF}$ & 270.15 & 1.29 & $\mathrm{BF}$ & 334.02 & 1.04 & $\mathrm{BF}$ & 417.53 & 0.83 \\
\hline A-12.9-1n & $\mathrm{BF}$ & 342.4 & $\mathrm{BF}$ & 263.58 & 1.30 & $\mathrm{BF}$ & 276.56 & 1.24 & $\mathrm{BF}$ & 346.87 & 0.99 & $\mathrm{BF}$ & 433.58 & 0.79 \\
\hline A-12.9-2 & $\mathrm{BF}$ & 392.0 & $\mathrm{BF}$ & 262.82 & 1.49 & $\mathrm{BF}$ & 280.97 & 1.40 & $\mathrm{BF}$ & 350.42 & 1.12 & $\mathrm{BF}$ & 438.03 & 0.89 \\
\hline A-12.9-3 & $\mathrm{BF}$ & 221.4 & $\mathrm{BF}$ & 173.86 & 1.27 & $\mathrm{BF}$ & 179.09 & 1.24 & $\mathrm{BF}$ & 225.72 & 0.98 & $\mathrm{BF}$ & 282.15 & 0.78 \\
\hline A-12.9-4 & $\mathrm{BF}$ & 426.0 & $\mathrm{BF}$ & 338.06 & 1.26 & $\mathrm{BF}$ & 341.41 & 1.25 & $\mathrm{BF}$ & 428.77 & 0.99 & SF & 509.28 & 0.84 \\
\hline A-12.9-5 & $\mathrm{BF}$ & 369.5 & $\mathrm{BF}$ & 263.20 & 1.40 & $\mathrm{BF}$ & 262.29 & 1.41 & $\mathrm{BF}$ & 328.38 & 1.13 & $\mathrm{BF}$ & 410.48 & 0.90 \\
\hline A-12.9-5n & $\mathrm{BF}$ & 342.4 & $\mathrm{BF}$ & 259.40 & 1.32 & $\mathrm{BF}$ & 249.54 & 1.37 & $\mathrm{BF}$ & 310.25 & 1.10 & $\mathrm{BF}$ & 387.81 & 0.88 \\
\hline A-12.9-6 & $\mathrm{BF}$ & 362.8 & $\mathrm{BF}$ & 260.73 & 1.39 & $\mathrm{BF}$ & 269.32 & 1.35 & $\mathrm{BF}$ & 330.69 & 1.10 & $\mathrm{BF}$ & 413.37 & 0.88 \\
\hline A-12.9-6n & $\mathrm{BF}$ & 365.8 & $\mathrm{BF}$ & 258.65 & 1.41 & $\mathrm{BF}$ & 263.93 & 1.39 & $\mathrm{BF}$ & 325.72 & 1.12 & $\mathrm{BF}$ & 407.15 & 0.90 \\
\hline A-12.9-7 & $\mathrm{BF}$ & 249.0 & $\mathrm{BF}^{*}$ & $264.90 *$ & $0.94 *$ & $\mathrm{BF}$ & 165.94 & 1.50 & $\mathrm{BF}$ & 169.71 & 1.47 & $\mathrm{BF}$ & 212.14 & 1.17 \\
\hline A-12.9-7n & $\mathrm{BF}$ & 250.4 & $\mathrm{BF}^{*}$ & $263.95 *$ & $0.95^{*}$ & $\mathrm{BF}$ & 169.04 & 1.48 & $\mathrm{BF}$ & 175.09 & 1.43 & $\mathrm{BF}$ & 218.86 & 1.14 \\
\hline A-12.9-8 & $\mathrm{BF}$ & 303.4 & $\mathrm{BF}^{*}$ & $271.54 *$ & $1.12 *$ & $\mathrm{BF}$ & 229.16 & 1.32 & $\mathrm{BF}$ & 267.01 & 1.14 & $\mathrm{BF}$ & 333.77 & 0.91 \\
\hline A-12.9-8n & $\mathrm{BF}$ & 304.6 & $\mathrm{BF}^{*}$ & $270.97 *$ & $1.12 *$ & $\mathrm{BF}$ & 224.98 & 1.35 & $\mathrm{BF}$ & 261.22 & 1.17 & $\mathrm{BF}$ & 326.52 & 0.93 \\
\hline A-12.9-9 & $\mathrm{BF}$ & 457.0 & $\mathrm{BF}$ & 261.68 & 1.75 & $\mathrm{BF}$ & 323.71 & 1.41 & $\mathrm{BF}$ & 348.91 & 1.31 & $\mathrm{BF}$ & 436.13 & 1.05 \\
\hline A-12.9-9n & $\mathrm{BF}$ & 456.5 & $\mathrm{BF}$ & 261.87 & 1.74 & $\mathrm{BF}$ & 320.21 & 1.43 & $\mathrm{BF}$ & 349.16 & 1.31 & $\mathrm{BF}$ & 436.45 & 1.05 \\
\hline B-12.9-3 & $\mathrm{BF}$ & 670.0 & $\mathrm{BF}$ & 518.81 & 1.29 & $\mathrm{BF}$ & 561.76 & 1.19 & $\mathrm{BF}$ & 691.74 & 0.97 & $\mathrm{NF}$ & 713.36 & 0.94 \\
\hline B-12.9-3n & $\mathrm{BF}$ & 682.5 & $\mathrm{BF}$ & 528.67 & 1.29 & $\mathrm{BF}$ & 565.29 & 1.21 & $\mathrm{BF}$ & 702.51 & 0.97 & NF & 723.54 & 0.94 \\
\hline C-12.9-1 & NF & 438.0 & $\mathrm{NF}^{*}$ & $347.69^{*}$ & $1.26^{*}$ & $\mathrm{BF}^{*}$ & $354.66^{*}$ & $1.23 *$ & $\mathrm{NF}^{*}$ & $424.20 *$ & $1.03 *$ & $\mathrm{NF}^{*}$ & $424.20 *$ & $1.03^{*}$ \\
\hline C-12.9-1n & $\mathrm{NF}$ & 447.0 & $\mathrm{NF}^{*}$ & $345.66^{*}$ & $1.29 *$ & $\mathrm{BF}^{*}$ & $351.47 *$ & $1.27^{*}$ & $\mathrm{NF}^{*}$ & $421.72 *$ & $1.06^{*}$ & $\mathrm{NF}^{*}$ & $421.72 *$ & $1.06^{*}$ \\
\hline C-12.9-2 & $\mathrm{NF}$ & 585.0 & NF* & $449.92 *$ & $1.30^{*}$ & $\mathrm{BF}$ & 475.55 & 1.23 & $\mathrm{NF}$ & 548.93 & 1.07 & $\mathrm{NF}$ & 548.93 & 1.07 \\
\hline C-12.9-2n & $\mathrm{NF}$ & 606.0 & $\mathrm{NF}^{*}$ & $455.75^{*}$ & $1.33^{*}$ & $\mathrm{BF}$ & 482.92 & 1.25 & $\mathrm{NF}$ & 556.04 & 1.09 & NF & 556.04 & 1.09 \\
\hline C-12.9-3 & $\mathrm{BF}$ & 684.5 & $\mathrm{BF}$ & 521.08 & 1.31 & $\mathrm{BF}$ & 536.14 & 1.28 & $\mathrm{BF}$ & 674.20 & 1.02 & NF & 704.98 & 0.97 \\
\hline C-12.9-3n & $\mathrm{BF}$ & 674.0 & $\mathrm{BF}$ & 518.81 & 1.30 & $\mathrm{BF}$ & 526.73 & 1.28 & $\mathrm{BF}$ & 654.22 & 1.03 & $\mathrm{NF}$ & 700.25 & 0.96 \\
\hline C-12.9-4 & $\mathrm{BF}$ & 483.5 & $\mathrm{BF}$ & $528.67^{*}$ & $0.91 *$ & $\mathrm{BF}$ & 326.30 & 1.48 & $\mathrm{BF}$ & 330.07 & 1.46 & $\mathrm{BF}$ & 412.58 & 1.17 \\
\hline C-12.9-4n & $\mathrm{BF}$ & 418.2 & $\mathrm{BF}$ & $519.57^{*}$ & $0.80^{*}$ & $\mathrm{BF}$ & 329.44 & 1.27 & $\mathrm{BF}$ & 339.54 & 1.23 & $\mathrm{BF}$ & 424.42 & 0.99 \\
\hline C-12.9-5 & $\mathrm{BF}$ & 557.5 & $\mathrm{BF}$ & $525.63 *$ & $1.06^{*}$ & $\mathrm{BF}$ & 424.68 & 1.31 & $\mathrm{BF}$ & 489.02 & 1.14 & $\mathrm{BF}$ & 611.27 & 0.91 \\
\hline C-12.9-5n & $\mathrm{BF}$ & 560.5 & $\mathrm{BF}$ & $525.63 *$ & $1.07 *$ & $\mathrm{BF}$ & 424.36 & 1.32 & $\mathrm{BF}$ & 490.68 & 1.14 & $\mathrm{BF}$ & 613.35 & 0.91 \\
\hline C-12.9-6 & $\mathrm{NF}$ & 720.0 & $\mathrm{BF}$ & 519.57 & 1.39 & $\mathrm{NF}$ & 636.01 & 1.13 & $\mathrm{BF}$ & 692.76 & 1.04 & $\mathrm{NF}$ & 706.68 & 1.02 \\
\hline C-12.9-6n & $\mathrm{NF}$ & 714.5 & $\mathrm{BF}$ & 516.15 & 1.38 & $\mathrm{NF}$ & 633.97 & 1.13 & $\mathrm{BF}$ & 688.20 & 1.04 & $\mathrm{NF}$ & 704.41 & 1.01 \\
\hline A-10.9-1 & SF & 278.4 & $\mathrm{BF}$ & 209.34 & 1.33 & $\mathrm{BF}$ & 208.49 & 1.34 & $\mathrm{SF}$ & 227.58 & 1.22 & SF & 227.58 & 1.22 \\
\hline A-10.9-1n & $\mathrm{SF}$ & 264.4 & $\mathrm{BF}$ & 212.83 & 1.24 & $\mathrm{BF}$ & 210.58 & 1.26 & $\mathrm{SF}$ & 249.27 & 1.06 & $\mathrm{SF}$ & 249.27 & 1.06 \\
\hline A-10.9-2 & $\mathrm{BF}$ & 369.2 & $\mathrm{BF}$ & 261.87 & 1.41 & $\mathrm{BF}$ & 264.29 & 1.40 & $\mathrm{BF}$ & 327.16 & 1.13 & $\mathrm{SF}$ & 371.88 & 0.99 \\
\hline A-10.9-2n & $\mathrm{BF}$ & 388.8 & $\mathrm{BF}$ & 258.46 & 1.50 & $\mathrm{BF}$ & 243.44 & 1.60 & $\mathrm{BF}$ & 294.81 & 1.32 & $\mathrm{BF}$ & 368.52 & 1.06 \\
\hline B-10.9-1 & SF & 544.5 & $\mathrm{BF}$ & 418.99 & 1.30 & $\mathrm{BF}$ & 468.68 & 1.16 & SF & 498.54 & 1.09 & $\mathrm{SF}$ & 498.54 & 1.09 \\
\hline B-10.9-1n & $\mathrm{SF}$ & 526.5 & $\mathrm{BF}$ & 423.24 & 1.24 & $\mathrm{BF}$ & 469.45 & 1.12 & SF & 498.54 & 1.06 & $\mathrm{SF}$ & 498.54 & 1.06 \\
\hline B-10.9-2 & $\mathrm{BF}$ & 683.0 & $\mathrm{BF}$ & 543.46 & 1.26 & $\mathrm{BF}$ & 585.36 & 1.17 & $\mathrm{BF}$ & 724.61 & 0.94 & $\mathrm{SF}$ & 743.76 & 0.92 \\
\hline B-10.9-2n & $\mathrm{BF}$ & 665.0 & $\mathrm{BF}$ & 521.84 & 1.27 & $\mathrm{BF}$ & 566.03 & 1.17 & $\mathrm{BF}$ & 695.79 & 0.96 & $\mathrm{NF}$ & 717.42 & 0.93 \\
\hline C-10.9-1 & $\mathrm{SF}$ & 593.0 & $\mathrm{BF}$ & 414.74 & 1.43 & $\mathrm{BF}$ & 424.27 & 1.40 & SF & 455.15 & 1.30 & SF & 455.15 & 1.30 \\
\hline C-10.9-1n & $\mathrm{SF}$ & 516.0 & $\mathrm{BF}$ & 417.78 & 1.24 & $\mathrm{BF}$ & 433.82 & 1.19 & $\mathrm{SF}$ & 498.54 & 1.04 & $\mathrm{SF}$ & 498.54 & 1.04 \\
\hline C-10.9-2 & $\mathrm{SF}$ & 558.0 & $\mathrm{BF}$ & 421.11 & 1.33 & $\mathrm{BF}$ & 411.72 & 1.36 & SF & 455.15 & 1.23 & $\mathrm{SF}$ & 455.15 & 1.23 \\
\hline C-10.9-2n & SF & 497.5 & $\mathrm{BF}$ & 436.28 & 1.14 & $\mathrm{BF}$ & 429.91 & 1.16 & SF & 498.54 & 1.00 & $\mathrm{SF}$ & 498.54 & 1.00 \\
\hline C-10.9-3 & $\mathrm{NF}$ & 613.5 & $\mathrm{NF}^{*}$ & $460.42 *$ & $1.33^{*}$ & $\mathrm{BF}$ & 486.93 & 1.26 & $\mathrm{NF}$ & 561.73 & 1.09 & $\mathrm{NF}$ & 561.73 & 1.09 \\
\hline C-10.9-3n & $\mathrm{NF}$ & 587.5 & $\mathrm{NF}^{*}$ & $446.23 *$ & $1.32 *$ & $\mathrm{BF}$ & 464.80 & 1.26 & NF & 544.42 & 1.08 & $\mathrm{NF}$ & 544.42 & 1.08 \\
\hline C-10.9-4 & $\mathrm{BF}$ & 682.5 & $\mathrm{BF}$ & 517.29 & 1.32 & $\mathrm{BF}$ & 520.46 & 1.31 & $\mathrm{BF}$ & 650.32 & 1.05 & NF & 696.62 & 0.98 \\
\hline C-10.9-4n & $\mathrm{BF}$ & 715.0 & $\mathrm{BF}$ & 524.50 & 1.36 & $\mathrm{BF}$ & 531.50 & 1.35 & $\mathrm{BF}$ & 665.24 & 1.07 & $\mathrm{NF}$ & 709.89 & 1.01 \\
\hline
\end{tabular}


Table 14

The average value of the ratio of experimental results and standard calculated values with different failure modes

\begin{tabular}{|c|c|c|c|c|}
\hline Failure mode & GB50017-2017 & Eurocode 3 & $\begin{array}{l}\text { AISC360-10 } \\
\text { method } 1\end{array}$ & $\begin{array}{c}\text { AISC360-10 } \\
\text { method } 2\end{array}$ \\
\hline $\mathrm{BF}$ & 1.28 & 1.34 & 1.14 & 0.95 \\
\hline NF & 1.29 & 1.21 & 1.06 & 1.05 \\
\hline SF & 1.36 & 1.25 & 1.12 & 1.12 \\
\hline Average & 1.30 & 1.31 & 1.12 & 1.00 \\
\hline Standard deviation & 0.127 & 0.108 & 0.132 & 0.115 \\
\hline
\end{tabular}

Table 15

The accuracy of the predicted failure mode for different failure modes specimens

\begin{tabular}{|c|c|c|c|c|}
\hline Failure mode & GB50017-2017 & Eurocode 3 & AISC360-10 method 1 & AISC360-10 method 2 \\
\hline $\mathrm{BF}$ & $100 \%$ & $100 \%$ & $100 \%$ & $65.5 \%$ \\
\hline NF & $0 \%$ & $33.3 \%$ & $66.7 \%$ & $100 \%$ \\
\hline SF & $0 \%$ & $0 \%$ & $100 \%$ & $100 \%$ \\
\hline Total & $67.7 \%$ & $72.1 \%$ & $95.4 \%$ & $76.7 \%$ \\
\hline
\end{tabular}

\section{Table 16}

Comparison between experimental results and the calculated values of B-12.9-3n

\begin{tabular}{|c|c|c|c|c|c|c|c|c|c|c|c|c|c|}
\hline \multirow{3}{*}{$\begin{array}{c}e_{1} \\
/ \mathrm{mm}\end{array}$} & \multirow{3}{*}{$\begin{array}{c}p_{1} \\
/ \mathrm{mm}\end{array}$} & \multirow{3}{*}{$\begin{array}{l}F_{\mathrm{U}, \mathrm{B}} \\
/ \mathrm{kN}\end{array}$} & \multirow{3}{*}{$\begin{array}{l}F_{\mathrm{U}, \mathrm{A}} \\
/ \mathrm{kN}\end{array}$} & \multirow{3}{*}{$F_{\mathrm{u}, \mathrm{B}} / F_{\mathrm{u}, \mathrm{A}}$} & \multicolumn{9}{|c|}{ Calculated value $(\mathrm{kN})$} \\
\hline & & & & & \multicolumn{3}{|c|}{ GB50017-2017 } & \multicolumn{3}{|c|}{ Eurocode 3} & \multicolumn{3}{|c|}{ AISC360-10 method 1} \\
\hline & & & & & Outer bolt & Inner bolt & Connection & Outer bolt & Inner bolt & Connection & Outer bolt & Inner bolt & Connection \\
\hline 51.35 & 70.18 & 682.5 & 342.5 & $199 \%$ & 284.58 & 284.58 & 569.16 & 277.38 & 287.92 & 565.29 & 350.07 & 352.45 & 702.51 \\
\hline
\end{tabular}

$F_{\mathrm{U}, \mathrm{B}}$ is the test load-carrying capacity of the specimen B-12.9-3n, $F_{\mathrm{U}, \mathrm{A}}$ is the test load-carrying capacity of A-series specimen with a similar end distance.

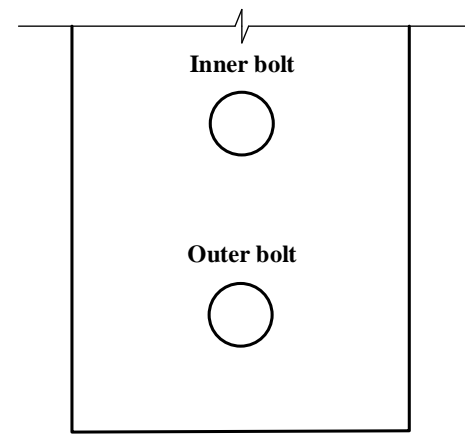

Fig. 16 B-series specimen schematic

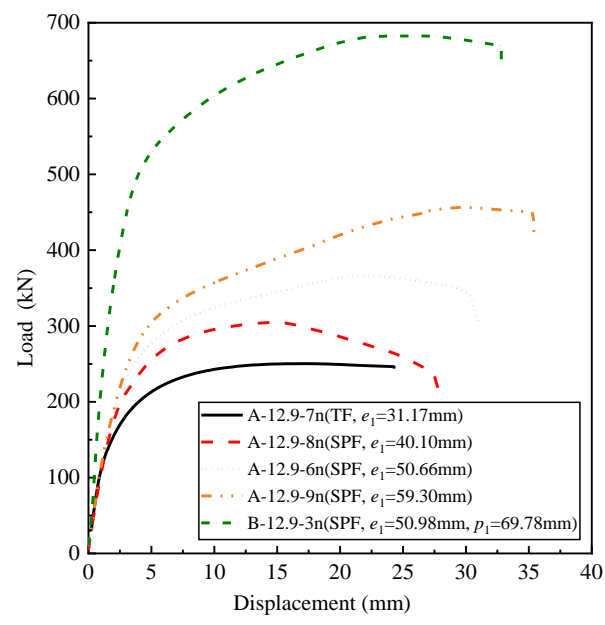

Fig. 17 Load displacement curves of specimens with different end distance

\section{Conclusion}

In this study, static tensile tests were performed on 45 sets of bearing-type connections that combine with Q345 steel and high-strength bolt, and five failure modes were observed. Based on the test results, the influence of the thickness and geometrical dimensions of the test plates, and the property grade, diameter, pretension, layout of the bolts were studied. Moreover, the experimental resistances were compared with the calculated values employed the design methods in GB50017-2017, Eurocode 3 and AISC360-10. And finally, the applicability of the code formula to the B-series specimens was discussed. The conclusions can be drawn as follows:

(1)There are five failure modes that the bearing-type shear connection may occur with: Tearout failure, splitting failure, pure bearing failure, net crosssection failure and bolt shear failure.

(2)Bolt specifications significantly affected the failure mode, primarily controlling the occurrence of the bolt shear failure modes. The bearing capacity of splitting failure specimens in this test was positively correlated with the thickness of the steel.

(3) The pretension of bolts affects little on the load-carrying capacity of specimens with the tearout failure, splitting failure and net cross-section failure, while it improved the load-carrying capacity and peak displacement of the specimen with bolt shear failure, and the increase in value was approximately $9.8 \% \sim 30.7 \%$ of the slip load. Meanwhile, the bolt pretension improved the stiffness of the connection at the friction stage and the bolt bar extrusion stage; however, the stiffness decreased rapidly when the specimen was approaching failing.

(4)The influence of geometrical dimensions on the load-carrying capacity and failure mode of the connections can be concluded as: when the end distance was in the range from $1.35 d_{0}$ to $2.67 d_{0}$, the carrying capacities of the specimens with tearout failure and splitting failure were positively correlated with the end distance. And when the edge distance was in the range from $1.77 d_{0}$ to $2.78 d_{0}$, the edge distance affected little on the carrying capacities of the specimens with splitting failure, and the load-carrying capacities of the specimens with net cross-section failure were positively correlated with the edge distance.

(5)The calculation methods in GB50017-2017 and Eurocode 3 were conservative for predicting the load-carrying capacity of connections that combine with Q345 steel and 10.9S or 12.9S bolts, and the calculated values that using AISC360-10 method 2 was the closest to the experimental results. The safety reserve of the bearing capacity, bolt shear capacity, and net crosssection capacity in the code formula had a decisive influence on the accuracy for predicting the failure mode. 
(6)For the shear connection with two bolts arranged parallelly to the load, the resistance calculated by the simple summation method in Eurocode 3 or AISC360-10 may be significantly higher than the actual load-carrying capacity.

\section{References}

[1] Fisher J.W., Ramseier P.O. and Beedle L.S., "Strength of a440 steel joints connected with a325 bolts", Publication IABSE, Vol. 23, Reprint 245 (63-24), 1963.

[2] Fisher J.W. and Rumpf J.L., "Analysis of bolted butt joints", Journal of the Structural Division, 91, 181-203, 1964

[3] Sterling G.H., "A440 steel butt join ts connected with high strength bolts or rivets", LehighUniversity, 1965 .

[4] Sterling G.H. and Fisher J.W., "A440 Steel Joints Connected by A490 Bolts", Journal of the Structural Division, 92, 101-118, 1965.

[5] Može P. and Beg D., "A complete study of bearing stress in single bolt connections", Journal of Constructional Steel Research, 95, 126-140, 2014

[6] Wang Y.B., Lyu Y.F., Li G.Q. and Liew J.Y. R., "Behavior of single bolt bearing on high strength steel plate", Journal of Constructional Steel Research, 137, 19-30, 2017.

[7] Rex C.O. and Easterling W.S., "Behavior and modeling of a bolt bearing on a single plate", Journal of Structural Engineering, 129(6), 792-800, 2003.

[8] Može P. and Beg D., "High strength steel tension splices with one or two bolts", Journal of Constructional Steel Research, 66(8-9), 1000-1010, 2010.

[9] Lyu Y.F., Wang Y.B., Li G.Q. and Jiang J., "Numerical analysis on the ultimate bearing resistance of single-bolt connection with high strength steels", Journal of Constructional Steel Research, 153, 118-129, 2019

[10] Wang Y.B., Lyu Y.F., Li G.Q. and Liew J.Y. R., "Bearing-strength of high strength steel plates in two-bolt connections", Journal of Constructional Steel Research, 155, 205-218, 2019.

[11] Lyu Y.F., Li G.Q., Wang Y.B., Li H. and Wang Y.Z., "Bearing behavior of multi-bolt high strength steel connections", Engineering Structures, 212, 110510, 2020.

[12] Može P., and Beg D., "Investigation of high strength steel connections with several bolts in double shear", Journal of constructional steel research, 67(3), 333-347, 2011.

[13] Može P., "Bearing strength at bolt holes in connections with large end distance and bolt pitch", Journal of Constructional Steel Research, 147, 132-144, 2018.

[14] Jiang K., Zhao O. and Tan K.H., "Experimental and numerical study of S700 high strength steel double shear bolted connections in tension", Engineering Structures, 225: 111175, 2020.

[15] Kim H.J. and Yura J.A. "The effect of ultimate-to-yield ratio on the bearing strength of bolted connections", Journal of Constructional Steel Research, 49(3), 255-269, 1999.

[16] Li D, Brian Uy., Wang J. and Song Y., "Behaviour and design of high-strength Grade 12.9 bolts under combined tension and shear", Journal of Constructional Steel Research, 174,

\section{Acknowledgments}

This research is supported by the National Natural Science Foundation of China (NSFC-51578089) and 111 Project (Grant No. B18062)

$106305,2020$.

[17] Nie S.D., Kang S.B, Shen L. and Yang B., "Experimental and numerical study on global buckling of Q460GJ steel box columns under eccentric compression", Engineering Structures, $142,211-222,2017$.

18] Nie S.D, Wu D., Yu X., Liu P. and Zhang W.F., "Global Buckling Behavior of Welded Thick H-Shaped Axial Compression Columns of Q460GJ Steel", Journal of Materials in Civil Engineering, 33(1), 04020398, 2021

[19] Yang B., Kang S.B, Xiong G., Nie S.D., Hu Y., Wang S.B., Bai J.B. and Dai G.X., "Experimental and numerical study on lateral-torsional buckling of singly symmetric Q460GJ steel I-shaped beams", Thin-Walled Structures, 113, 205-216, 2017.

[20] Zeng B., Dai G.X. and Xia Z.Z., "Reliability evaluation of high strength bolt connections", Industrial Construction, 27(6), 44-49, 1997. (in Chinese)

[21] Zeng B. and Xia Z.Z., "Pattern Classification Analysis Based on Fuzzy Relation of UncertainInfluence-Factors in High-Strength-Bolt Connections", Journal of Civil, Architectural and Environmental Engineering, S1, 52-58, 1992. (in Chinese)

[22] Dai G.X., "Research and evaluation of reliability of building steel structure", Chongqing university, 2004. (in Chinese)

[23] Hou Z.X. "Study on performance of bearing-type high-strength bolt connection", Industrial Construction, 9, 24-27, 1992. (in Chinese)

[24] GBJ17-88, Code for design of steel structures., Ministry of metallurgical industry of China, Beijing, China, 1988. (in Chinese)

[25] GB 50017-2017, Standard for design of steel structures., Ministry of Housing and UrbanRural Development of the People's Republic of China \& General Administration of Quality Supervision, Inspection and Quarantine of the People's Republic of China, Beijing, China, 2017. (in Chinese)

[26] EN 1993-1-8, Eurocode 3: Design of Steel Structures - Part 1-8: Design of Joints., European Committee for Standardisation, Brussels, Belgium, 2005.

[27] ANSI/AISC 360-10, Specification for Structural Steel Buildings., American Institute of Stee Construction, Chicago, America, 2010.

[28] GB/T 1231-2006, High strength bolts with large hexagon head, large hexagon nuts, plain washers and specification for steel structures., General Administration of Quality Supervision, Inspection and Quarantine of the People's Republic of China \& China National Standardization Administration Committee, Beijing, China, 2006. (in Chinese)

[29] JGJ 82-2011, Technical specification for high strength bolt connection of Steel Structures. Ministry of Housing and Urban-Rural Development of the People's Republic of China, Beijing, China, 2011. (in Chinese) 